\title{
Herpes Simplex Virus Type 1 Infects Enteric Neurons and Triggers Gut Dysfunction via Macrophage Recruitment
}

\author{
Paola Brun ${ }^{1 *}$, Marsela Qesari ${ }^{2 \dagger}$, Peggy C. Marconi ${ }^{3}$, Andromachi Kotsafti ${ }^{4}$, \\ Andrea Porzionato ${ }^{5}$, Veronica Macchi ${ }^{5}$, Reto A. Schwendener ${ }^{6 \neq}$, Marco Scarpa $^{4}$, \\ Maria C. Giron ${ }^{2}$, Giorgio Palù ${ }^{1}$, Arianna Calistri ${ }^{1}$ and Ignazio Castagliuolo ${ }^{1}$ \\ ${ }^{1}$ Department of Molecular Medicine, University of Padova, Padova, Italy, ${ }^{2}$ Department of Pharmaceutical and \\ Pharmacological Sciences, University of Padova, Padova, Italy, ${ }^{3}$ Department of Life Sciences and Biotechnology, University \\ of Ferrara, Ferrara, Italy, ${ }^{4}$ Esophageal and Digestive Tract Surgery Unit, Veneto Institute of Oncology IOV-IRCCS, Padova, \\ Italy, ${ }^{5}$ Department of Neurosciences, University of Padova, Padova, Italy, ${ }^{6}$ Institute of Molecular Cancer Research, University \\ of Zurich, Zurich, Switzerland
}

Herpes Simplex Virus type 1 (HSV-1), a neurotropic pathogen widespread in human population, infects the enteric nervous system (ENS) in humans and rodents and causes intestinal neuromuscular dysfunction in rats. Although infiltration of inflammatory cells in the myenteric plexus and neurodegeneration of enteric nerves are common features of patients suffering from functional intestinal disorders, the proof of a pathogenic link with HSV-1 is still unsettled mainly because the underlying mechanisms are largely unknown. In this study we demonstrated that following intragastrical administration HSV-1 infects neurons within the myenteric plexus resulting in functional and structural alterations of the ENS. By infecting mice with HSV-1 replication-defective strain we revealed that gastrointestinal neuromuscular anomalies were however independent of viral replication. Indeed, enteric neurons exposed to UV-inactivated HSV-1 produced monocyte chemoattractant protein-1 (MCP-1/CCL2) to recruit activated macrophages in the longitudinal muscle myenteric plexus. Infiltrating macrophages produced reactive oxygen and nitrogen species and directly harmed enteric neurons resulting in gastrointestinal dysmotility. In HSV-1 infected mice intestinal neuromuscular dysfunctions were ameliorated by in vivo administration of (i) liposomes containing dichloromethylene bisphosphonic acid (clodronate) to deplete tissue macrophages, (ii) CCR2 chemokine receptor antagonist RS504393 to block the CCL2/CCR2 pathway, (iii) $\mathrm{N} \omega$-Nitro-L-arginine methyl ester hydrochloride (L-NAME) and AR-C 102222 to quench production of nitrogen reactive species produced via iNOS. Overall these data demonstrate that HSV-1 infection makes enteric neurons recruit macrophages via production of a specific chemoattractant factor. The resulting inflammatory reaction is mandatory for intestinal dysmotility. These findings provide insights into the neuro-immune communication that occurs in the ENS following HSV-1 infection and allow recognition of an original pathophysiologic mechanism underlying gastrointestinal diseases as well as identification of novel therapeutic targets.

Keywords: neurotropic virus, enteric neuropathies, inflammation, neuromuscular dysfunction, macrophage recruitment 


\section{INTRODUCTION}

Herpes simplex virus type 1 (HSV-1) is counted among the most common viruses establishing chronic infections in humans (Straus, 2000). During primary infection, HSV-1 replicates in mucoepithelial cells of the mouth and throat. As neurotropic virus, it then gains access to sensory neurons and starts a latent infection, generally in the trigeminal ganglia (Swanson and McGavern, 2015). Throughout latency, HSV-1 expresses a unique pattern of RNAs, so-called LATs, persisting for the life of the host (Wilson and Mohr, 2012). The idea that HSV-1 is completely inactive during latency has been recently challenged since viral antigens expressed on latently infected human trigeminal ganglia mount a chronic inflammatory response impacting neuronal phenotype and function (van Velzen et al., 2013; Menendez et al., 2016). Latent HSV-1 periodically reactivates and travels through neuronal axons to the mucosal epithelium resulting in symptomatic or asymptomatic infections. Both infections similarly shed viral particles in the saliva and ensure transmission to immune competent individuals or secondary places in the same host (Straus, 2000; Kaufman et al., 2005; Miller and Danaher, 2008). By swallowing, infectious particles possibly reach the mucosa of the gastrointestinal tract and thereafter the enteric neurons embedded in the gut wall (Brun et al., 2010; Koyuncu et al., 2013). Indeed, HSV-1 DNA has been demonstrated in human nodose and celiac ganglia, neuronal structures innervating the gastrointestinal tract (Rand et al., 1984; Gesser and Koo, 1997). While in the central nervous system the HSV-1-driven inflammatory response has been linked to longterm neurologic deficits (Menendez et al., 2016) it is not clear how and at which extent HSV-1 infection impacts the functional integrity of the enteric neurons.

The innate and adaptive immune responses strongly crossinteract to control HSV-1 infection and to maintain the viral genome in the latent state. Pattern recognition receptors of the innate immunity recognize viral fragments and trigger secretion of interferons and cytokines which in turn shape specific adaptive immune responses to guarantee the immune surveillance in the infected tissue (Virgin et al., 2009; Koyuncu et al., 2013; Khoury-Hanold et al., 2016). The effectiveness of the immune response during HSV-1 infection strongly relies on the recruitment and differentiation of monocytes into tissue macrophages endowed with remarkable antiviral activities (Ellermann-Eriksen, 2005). Indeed, macrophages clear viral particles and apoptotic cells, release pro-inflammatory cytokines and chemokines to attract additional innate immune cells, limit viral replication, process, and present viral antigens to lymphocytes (Kodukula et al., 1999). Quite the opposite, infiltrating macrophages producing pro-inflammatory cytokines have been described also during latent HSV-1 infection and correlate with prolonged neuroinflammation in hypothalamus

Abbreviations: LMMP, longitudinal muscle myenteric plexus; ENS, enteric nervous system; IN, intranasal; IG, intragastric; MCP-1/CCL2, monocyte chemoattractant protein-1; HSV-1, Herpes simplex virus type 1; WT, wild-type; LNAME, N $\omega$-Nitro-L-arginine methyl ester hydrochloride; iNOS, inducible nitric oxide synthase; EFS, electric field stimulation; NANCL non-adrenergic noncholinergic. and hippocampus (White et al., 2016). Indeed, during chronic HSV-1 infection recruited immune cells impact the integrity of peripheral nerves either directly by damaging neurons harboring the virus or through the secretion of soluble factors that modify gene expression and survival of infected and non-infected cells (Kramer et al., 2003; Dosa et al., 2011).

We have recently described the first animal model of persistent HSV-1 infection in the enteric nervous system (ENS) thus providing the proof of concept that neurotropic viruses can reach enteric nerves and cause intestinal neuromuscular abnormalities (Brun et al., 2010). Since anti-inflammatory drugs have proved effective for treating patients suffering from gastrointestinal neuropathies, in this study we investigated the involvement of immune mediated mechanisms during the early phases of HSV1-induced damage of the ENS. We demonstrated that HSV1 triggers expression of monocyte chemoattractant protein-1 (MCP-1/CCL2) in enteric neurons thus recruiting macrophages in the myenteric ganglia. Infiltrating macrophages in turn produce reactive nitrogen species which cause structural and functional anomalies of the ENS resulting in gastrointestinal dysmotility.

\section{MATERIALS AND METHODS}

\section{Viral Stocks Preparation and Titration}

Replicating HSV-1 strain SC16 and replication-defective HSV-1 mutants lacking the immediate-early genes coding for infected cell polypeptide (ICP)27 (HSV-1 IGR20 $\triangle \mathrm{ICP} 27 \mathrm{gJHE}$ ) or for ICP4, ICP27, and ICP22 (HSV-1 T0Z $\triangle I C P 4 . I C P 27 . I C P 22 . U L 41)$ were propagated on Vero cells (ATCC ${ }^{\circledR}$ CCL81 ${ }^{\mathrm{TM}}$, American Type Culture Collection, VA, USA) or on $7 \mathrm{~b}$ complementing cell lines, as previously described (Brun et al., 2010; Marconi et al., 2015). HSV-1 stocks were prepared in complete Dulbecco's modified Eagle's media (Gibco, $\mathrm{UK}$ ) to obtain $1 \times 10^{8}$ plaque-forming units $(\mathrm{PFU}) / \mathrm{mL}$.

\section{Mice Infection and Treatments}

Wild type (WT) C57BL/6J male mice, 8-10 weeks old, were purchased from Envigo Laboratories (Udine, Italy). Animals were housed in a temperature-controlled environment $(22 \pm$ $2^{\circ} \mathrm{C}$ ) under a $12 \mathrm{~h}$ light/dark cycle with food and water provided ad libitum. After 1 week acclimation period, mice were infected by intranasal (IN) instillation of HSV-1 strain SC16, $10^{2}$ PFU (10 $\mu \mathrm{L}$ final volume). Four weeks later, animals were inoculated via intragastric (IG) gavage (24 gauge, 9-cm catheter) with 1 $\times 10^{7}$ PFU of HSV-1 strain 16, HSV-1 IGR20 $\triangle \mathrm{ICP} 27 \mathrm{gJHE}$, HSV-1 T0Z $\triangle I C P 4 . I C P 27 . I C P 22 . U L 41$, or equal volumes of Vero cell lysate (sham infection). The two-step protocol of HSV-1 administration was set to avoid high animal mortality rate (Brun et al., 2010). Following IG inoculum, mice were observed daily for signs of disease and sacrificed after 1, 2, or 3 weeks. Sham infected mice were sacrificed at matching time points; since the results were comparable, data were pooled together and reported as one sham infected animal group. As described, mice were injected intraperitoneally with rat anti-mouse CD4 purified monoclonal antibody $(200 \mu \mathrm{g}$; clone GK1.5) for CD4 depletion; N $\omega$-Nitro-L-arginine methyl ester 
hydrochloride (L-NAME, $25 \mathrm{mg} / \mathrm{kg} /$ day, Sigma, Italy) (De Visser et al., 2010), 5-[(4'-Amino-5', $8^{\prime}$-difluorospiro[piperidine$4,2^{\prime}\left(1^{\prime} \mathrm{H}\right)$-quinaxolin]-1-yl)carbonyl]-2-pyridinecarbonitrile hydrochloride (AR-C102222, a selective iNOS inhibitor, 30 $\mathrm{mg} / \mathrm{kg} /$ day, Tocris Bioscience, UK) (LaBuda et al., 2006), CCR2 chemokine receptor antagonist (RS504393, $2 \mathrm{mg} / \mathrm{kg} / \mathrm{twice}$ a day, Tocris Bioscience, UK) (Kitagawa et al., 2004), empty liposomes, or liposomes containing dichloromethylene bisphosphonic acid (clodronate), referred to as Clodrolip (Zeisberger et al., 2006). Anti-CD4 monoclonal antibody was produced by hybridoma (ATCC ${ }^{\circledR}$ TIB $207^{\text {TM }}$ ) and purified using Protein G PLUS-Agarose (Santa Cruz Biotechnology, Italy). The initial dose of monoclonal antibody, L-NAME, AR-C102222 was administered immediately after IG HSV-1 inoculation and then for additional 7 days. The first dose of Clodrolip ( $1 \mathrm{mg} / 10 \mathrm{~g}$ body weight) was administered 5 days before IG HSV-1 inoculum and subsequently every $72 \mathrm{~h}(0.6 \mathrm{mg} / 10 \mathrm{~g}$ body weight $)$. Sham infected mice received equal volumes of vehicle or empty liposomes, as appropriate. All experimental protocols were approved by the Animal Care and Use Committee of the University of Padova under license from the Italian Ministry of Health and followed the National and European guidelines for handling and use of experimental animals.

\section{HSV-1 Infectivity and Reactivation Assays}

HSV-1 infectivity was evaluated in the content of ileum. Briefly, mice were inoculated IG with HSV-1 strain SC16 or vehicle (sham infection) as described above and sacrificed 15 or $45 \mathrm{~min}$ later. The gut was carefully dissected, and content of the ileum was collected by flushing $5 \mathrm{ml}$ sterile PBS. Samples were vigorously vortexed, centrifuged $(3,000 \mathrm{rpm}, 10 \mathrm{~min})$ at $4^{\circ} \mathrm{C}$, and equal volumes of the clarified supernatants were serially diluted and incubated with Vero cell monolayers. Vero cell cultures were monitored for up to $72 \mathrm{~h}$ to observe cytopathic effects. Cells were fixed and stained with crystal violet, and number of plaques was determined. Data are reported as percentage of the number of plaques obtained in Vero cells incubated directly with HSV-1 strain $16\left(1 \times 10^{7} \mathrm{PFU}\right)$. HSV-1 presence was confirmed by PCR analysis on DNA extracted from Vero cells.

\section{Intestinal Whole Mount Preparation and Staining}

At the time of sacrifice, $8 \mathrm{~cm}$ segment of the distal ileum was flashed with PBS, filled with 4\% PFA and submerged in the same fixative for $1 \mathrm{~h}$ at $22^{\circ} \mathrm{C}$. Tissues were then washed in PBS $(3 \times$ $10 \mathrm{~min}$ ) and stored at $4^{\circ} \mathrm{C}$ (Brun et al., 2013). Whole mounts were prepared from $1 \mathrm{~cm}$ long specimen under a dissecting microscope (Zeiss, Germany) by peeling off the longitudinal muscle layer containing the myenteric plexus (LMMP). LMMP were gently stretched, pinned down on a wax support, washed twice with PBS containing $0.5 \%$ Triton-X100, incubated in blocking buffer ( $2 \%$ bovine serum albumin, $0.5 \%$ Triton-X100 in PBS) and then stained at $4{ }^{\circ} \mathrm{C}$ for $16 \mathrm{~h}$ with primary antibody (Table $\mathbf{1}$ ). Fluorescent labeled secondary antibodies (Table 1) were used to detect immune-complexes using Leica TCSNT/SP2 confocal microscope.
TABLE 1 | Primary and secondary antibodies used in the study.

\begin{tabular}{|c|c|c|c|}
\hline Antigen (host) & Clone & Source & Application \\
\hline \multicolumn{4}{|c|}{ Primary antibodies } \\
\hline$\beta$ III-Tubulin (rabbit) & Polyclonal & Couvance & WM \\
\hline Peripherin (rabbit) & Polyclonal & Millipore & WM \\
\hline $\mathrm{S} 100 \beta$ (rabbit) & EP1576Y & Millipore & WM \\
\hline ChAT (rabbit) & Polyclonal & Gene Tex & WB \\
\hline nNOS (rabbit) & Polyclonal & Invitrogen & WB \\
\hline CCL2 (rat) & ECE.2 & Abcam & $\mathrm{IHC}$ \\
\hline$\beta$-Actin (mouse) & AC-15 & Sigma-Aldrich & WB \\
\hline CD3 (rat) & $17 \mathrm{~A} 2$ & eBioscience & $\mathrm{IHC}, \mathrm{FC}$ \\
\hline CD4 (rabbit) & 50134-R001 & Sino Biological Inc. & FC \\
\hline CD8 (rabbit) & orb1269 & Biorbyt Ltd & $\mathrm{FC}$ \\
\hline $\mathrm{IFN} \gamma($ rat) & XMG1.2 & eBioscience & FC \\
\hline IL4 (rat) & 11B11 & eBioscience & FC \\
\hline F4/80 (rat) & Cl:A3-1 & Abcam & FC \\
\hline CD11b (rabbit) & EPR1344 & Abcam & IHC, FC \\
\hline CD19 (rabbit) & $\mathrm{C} 1 \mathrm{C3}$ & Gene Tex & $\mathrm{FC}$ \\
\hline NK1.1 (rabbit) & PK136 & Gene Tex & FC \\
\hline gD (mouse) & $1-1-9$ & Abcam & WB \\
\hline gC (mouse) & $3 G 9$ & Abcam & WB \\
\hline \multicolumn{2}{|l|}{ Antigen (host) } & Source & Application \\
\hline \multicolumn{4}{|c|}{ Secondary antibodies } \\
\hline \multicolumn{2}{|c|}{ Anti-rabbit (goat) PE } & Chemicon & WM, FC, IHC \\
\hline \multicolumn{2}{|c|}{ Anti-rat (rabbit) FITC } & Invitrogen & $\mathrm{IHC}, \mathrm{FC}$ \\
\hline \multicolumn{2}{|c|}{ Anti-rabbit (goat) HRP } & Sigma-Aldrich & WB, IHC \\
\hline \multicolumn{2}{|c|}{ Anti-mouse (goat) HRP } & Sigma-Aldrich & WB \\
\hline \multicolumn{2}{|c|}{ Anti-rat (rabbit) HRP } & Sigma-Aldrich & $\mathrm{IHC}$ \\
\hline \multicolumn{2}{|c|}{ Anti-rabbit (goat) APC } & Chemicon & FC \\
\hline \multicolumn{2}{|l|}{ Anti-rat (rabbit) PE } & Sigma-Aldrich & FC \\
\hline
\end{tabular}

WB, western blot; WM, whole mount; IHC, immunohistochemistry; FC, flow cytometry.

\section{Isolation of Longitudinal Muscle Myenteric Plexus}

At the sacrifice, the small intestine was aseptically removed, washed in oxygenated Krebs solution $(126 \mathrm{mM} \mathrm{NaCl}, 2.5 \mathrm{mM}$ $\mathrm{KCl}, 25 \mathrm{mM} \mathrm{NaHCO} 3,1.2 \mathrm{mM} \mathrm{NaH} 2 \mathrm{PO} 4,1.2 \mathrm{mM} \mathrm{MgCl}$, $2.5 \mathrm{mM} \mathrm{CaCl} 2, \mathrm{pH} 7.2$ ) and cut in pieces of $1 \mathrm{~cm}$ length. Intestinal segments were placed on a sterile glass rod and a small incision was created in the longitudinal muscle by gently rub the edge of the forceps. The LMMP were then peeled off under a dissecting microscope (Zeiss, Germany) and immediately snap-frozen in liquid nitrogen or subjected to enzymatic digestion to isolate macrophages, lymphocytes, or enteric neurons.

\section{Isolation and Culture of Enteric Neurons}

Freshly obtained LMMP were rinsed three times in Krebs, minced with scissors and digested in $1.3 \mathrm{mg} / \mathrm{ml}$ collagenase type II (Sigma) and $0.3 \mathrm{mg} / \mathrm{ml}$ bovine serum albumin at $37^{\circ} \mathrm{C}$ for $15 \mathrm{~min}$. Cells were then co-cultured with Vero cells or seeded on laminin and poly-D-lysine (all from Sigma) coated coverslips in Neurobasal A media containing B-27 supplement, 
$1 \%$ fetal bovine serum, $10 \mathrm{ng} / \mathrm{mL}$ nerve growth factor (NGF, BioLegend, Italy), and penicillin/streptomycin. Half of the cell media was replaced every 2 days with fresh complete growth media (Brun et al., 2015). As indicate, at the fifth day in culture, neurons were incubated with HSV-1 for $36 \mathrm{~h}$ and then fixed in PFA $4 \%$ for $20 \mathrm{~min}$ at room temperature and subjected to immunocytochemistry following the same protocol described in 2.4. Alternatively, enteric neurons were challenged with HSV-1 inactivated by exposure to 20 Joules of ultraviolet (UV) light for $10 \mathrm{~min}$ at maximal power output.

\section{Nucleic Acid Extraction and Analysis}

Vero cells were homogenized in digestion buffer and DNA was extracted using "Tissue DNA Extraction Kit" (Millipore, Milan, Italy). LMMP were homogenized using a Retsch MM300 mixer and RNA was extracted using SV total RNA isolation system (Promega, Italy) following manufacturer's protocol. Contaminating DNA was removed by DNase I treatment (Promega). Complementary DNA (cDNA) was generated as previously described (Brun et al., 2013). To study HSV-1 reactivation and replication cycle, $5 \mu \mathrm{L}$ of cDNA were subjected to semi-quantitative PCR. Amplification products were separated on agarose gel and visualized by Nancy-520 DNA gel stain (Sigma, Milan, Italy) using UV illuminator. Quantitative PCR was performed using the ABI Prism 7700 Sequence Detection System (PerkinElmer, Monza, Italy) and iTaq Universal SYBR Green One-Step Kit (Bio-Rad Laboratories, CA, USA). Specific oligonucleotides were designed in two adjacent exons (Universal Probe Library Assay Design Center, Roche Applied Science) and are listed in Table 2. Data were normalized to $18 \mathrm{~S}$ ribosomal RNA (Rn18S) and plotted as mean fold changes.

TABLE 2 | Oligonucleotides and PCR conditions.

\begin{tabular}{|c|c|c|}
\hline Oligonucleotide & Sequence & $\operatorname{Tm}\left({ }^{\circ} \mathrm{C}\right)$ \\
\hline tk & $\begin{array}{l}\text { Fw } 5^{\prime} \text {-tagcccggccgtgtgaca-3' } \\
\text { Rv } 5^{\prime} \text {-cataccggaacgcaccacacaa }\end{array}$ & 60 \\
\hline LATs & $\begin{array}{l}\text { Fw } 5^{\prime} \text {-gacagcaaaacaataaggg--3' } \\
\text { Rv } 5^{\prime} \text {-acgagggaaaacaataaggg--3' }\end{array}$ & 60 \\
\hline ICP4 & $\begin{array}{l}\text { Fw 5'-atgacggggacgagtacgac-3' } \\
\text { Rv } 5^{\prime} \text {-acgacgaggacgaagaggat-3' }\end{array}$ & 56 \\
\hline VP16 & $\begin{array}{l}\text { Fw } 5^{\prime} \text {-tgcgggagctaaaccacatt-3' } \\
\text { Rv } 5^{\prime} \text {-tccaacttcgcccgaatcaa-3' }\end{array}$ & 60 \\
\hline gB & $\begin{array}{l}\text { Fw } 5^{\prime} \text {-ggctccttccgattctcc-3' } \\
\text { Rv } 5^{\prime} \text {-ggtactcggtcaggttggtg--3' }\end{array}$ & 60 \\
\hline $\mathrm{gC}$ & $\begin{array}{l}\text { Fw } 5^{\prime} \text {-ccaaacccaagaacaacacc--3' } \\
\text { Rv } 5^{\prime} \text {-tgttcgtcaggacctcctct- } 3^{\prime}\end{array}$ & 60 \\
\hline$\beta$-actin & $\begin{array}{l}\text { Fw } 5^{\prime} \text {-aggaagccactctagggagc- } 3^{\prime} \\
\text { Rv } 5^{\prime} \text {-agaacagagtgagcgggaga- } 3^{\prime}\end{array}$ & 60 \\
\hline Ccl2 & $\begin{array}{l}\text { Fw } 5^{\prime} \text {-gcctgctgttcacagttgc-3' } \\
\text { Rv } 5^{\prime} \text {-caggtgagtggggcgtta-3' }\end{array}$ & 60 \\
\hline Ccr2 & $\begin{array}{l}\text { Fw } 5^{\prime} \text {-acctgtaaatgccatgcaagt-3' } \\
\text { Rv 5'-tgtcttccatttcctttgatttg-3' }\end{array}$ & 60 \\
\hline Rn18S & $\begin{array}{l}\text { Fw } 5^{\prime} \text {-tcaagaacgaaagtcggagg-3' } \\
\text { Rv } 5^{\prime} \text {-ggacatctaagggcatca-3' }\end{array}$ & 60 \\
\hline
\end{tabular}

FW, forward; Rv, reverse; Tm, melting temperature.

\section{Histological Evaluation}

Mice were sacrificed at the specified time. Specimens of ileum (5$10 \mathrm{~cm}$ long segments starting from the ileocecal valve) were fixed in $10 \%$ neutral buffered formalin for $24 \mathrm{~h}$, embedded in paraffin and sectioned at $5 \mu \mathrm{m}$ thickness. Six representative sections per mouse were subjected to Hematoxylin and Eosin (H\&E) staining. A minimum of 10 independent fields per animal were examined using Leica microscope equipped with a digital camera.

\section{Immunohistochemistry}

Four $\mu \mathrm{m}$ thick sections were obtained from paraffin embedded samples of ileum, deparaffinized and rehydrated (xylene $5 \mathrm{~min}$; ethanol 100, 95, 70\%, 1 min each), using standard procedures (Brun et al., 2013). Slices were exposed to $10 \% \mathrm{H}_{2} \mathrm{O}_{2}$ to block endogenous peroxidase activity, treated with citrate buffer $(\mathrm{pH}$ 9) for antigen retrieval, and finally incubated with universal blocking solution (Lab Vision Corporation, CA, USA). Tissue sections were then exposed to proper antibody (Table 1) for $1 \mathrm{~h}$ at $22^{\circ} \mathrm{C}$. The Dako Envision+ System-HRP labeled Polymer Detection system (Dako, CA, USA) was used, with either $3,3^{\prime}$ diaminobenzidinetetrahydrochloride (DAB) as chromogenic substrate. Sections were H\&E counterstained and observed using conventional microscopy. As negative control, sections were stained either by isotype-matched antibody of inappropriate specificity or by omitting the primary antibody.

\section{Neurological Assessment}

Neurological integrity of each mouse was assessed twice a week by a blinded observer using a validated scoring system (Garcia et al., 1995). Six tests were performed to evaluate sensorimotor functions: (1) spontaneous activity; (2) symmetry in the movement of the four limbs; (3) forepaw outstretching; (4) climbing; (5) body proprioception; and (6) response to vibrissae touch.

\section{In Vivo Gastrointestinal Transit}

Mice were administered IG with fluorescein-isothiocyanate dextran (70,000 MW; $6.25 \mathrm{mg} / \mathrm{mL}$ in PBS; $100 \mu \mathrm{L} / \mathrm{mice}$; MP Biomedicals LLC, CA, USA). Animals were sacrificed $60 \mathrm{~min}$ later and the entire bowel was gently removed. Small intestine was divided in 8 equal segments whereas stomach, cecum and colon were examined separately. Luminal contents were collected and clarified by centrifugation $\left(10,000 \times \mathrm{g}, 15 \mathrm{~min}, 4^{\circ} \mathrm{C}\right)$. Fluorescence analysis was performed at $494 / 521 \mathrm{~nm}$ (Hitachi F2000; Hitachi, Tokyo, Japan). Gastric emptying was calculated as the percentage of FITC-dextran left in the stomach compared with the total amount of fluorescence in the gastrointestinal tract. Intestinal transit was reported as the geometric center of distribution of the fluorescent probe throughout the ileum (Brun et al., 2013).

\section{Distal Colonic Transit Measurements}

Distal colonic transit was assessed in fasted mice briefly anesthetized with isoflurane ( $<1 \mathrm{~min}$; Merial, France). As previously described (Martínez et al., 2002), a single 2-mm glass bead was inserted into the distal colon at $2 \mathrm{~cm}$ from the anus. After bead insertion, mice were placed individually in 
plastic cages lined with white paper to aid visualization of bead expulsion. Mice readily regained consciousness showing normal behavior. Distal colonic transit was determined to the nearest $0.1 \mathrm{~min}$ by monitoring the time required for the expulsion of the glass bead (bead retention).

\section{Ex Vivo Contractility Studies}

Ex vivo contractility studies were performed as previously described (Brun et al., 2013) on full-thickness distal ileum segments. Contractions were evoked by electrical field stimulation (EFS; 2-50 Hz, 1-ms pulse duration, 10-s pulse trains, $60 \mathrm{~V}$ ) using platinum electrodes connected to a S88 stimulator (Grass Instrument, MA, USA). When indicated, EFSinduced non-adrenergic, non-cholinergic (NANC) relaxation responses were obtained using increasing frequencies of stimulation $(2-40 \mathrm{~Hz})$ in presence or absence of L-NAME $100 \mu \mathrm{M}$.

\section{Immunoblot Analysis}

LMMP were lysed in RIPA buffer $(150 \mathrm{mM} \mathrm{NaCl}, 50 \mathrm{mM}$ Tris$\mathrm{HCl}, 0.25 \%$ sodium deoxycholate, $0.1 \%$ Nonidet P- $40,100 \mu \mathrm{M}$ $\mathrm{NaVO} 4,1 \mathrm{mM} \mathrm{NaF}$ ) containing a mixture of protease inhibitors (0.5 mM EDTA, $0.1 \mathrm{mM}$ PMSF, $1 \mu \mathrm{M}$ leupeptin, $150 \mathrm{nM}$ aprotinin) (Brun et al., 2013). Samples were incubated $30 \mathrm{~min}$ at $4^{\circ} \mathrm{C}$. Particulate material was removed by centrifugation $(15,000$ $\times \mathrm{g}, 5 \mathrm{~min}$ at $4^{\circ} \mathrm{C}$ ) and protein concentration was determined in the supernatants using the bicinchoninic acid assay (Thermo Scientific, MA, USA). Proteins (40 $\mu \mathrm{g} / \mathrm{line})$ were fractionated through SDS-PAGE gel and immobilized onto PVDF membrane (Bio-Rad Laboratories). Unspecific bindings were blocked for $1 \mathrm{~h}$ in 5\% non-fat dry milk dissolved in PBS and added with $0.05 \%$ Tween20. PVDF membranes were then probed with specific antibodies (Table 1). Immune-complexes were revealed using horseradish peroxidase (HRP)-conjugated secondary antibodies (Sigma-Aldrich, Italy; Table 1) and enhanced chemiluminescent substrate (ECL, Millipore, Italy). Images were captured using Hyper Film MP (GE Healthcare, Italy). Antibody against mouse $\beta$-actin (Sigma) was used as loading control. Densitometric analysis was performed using the ImageJ software (US National Institutes of Health).

\section{Serological Assay}

Blood samples $(\sim 1.0 \mathrm{ml})$ collected from sham, IN and IG HSV1 infected mice were incubated at room temperature for $60 \mathrm{~min}$ to allow clotting. Serum was then separated by centrifugation $(2,000 \mathrm{rpm}, 10 \mathrm{~min})$ and stored at $-20^{\circ} \mathrm{C}$ until it was used to determine the presence of anti-HSV-1 IgG using commercially available ELISA (Mouse/Rat HSV-1 IgG ELISA; Calbiotech, CA, USA) following manufacturer's protocol.

\section{Isolation of Mononuclear Cells}

To isolate lymphocytes, spleens were dissociated by forcing tissue through a $100 \mu \mathrm{m}$ metallic mesh. To obtain lymphocytes and macrophages from LMMP, freshly isolated ileum was cut in small pieces and LMMP peeled off. Then, LMMP were finely minced using scissors and dissociated by incubation for $10 \mathrm{~min}$ at $37^{\circ} \mathrm{C}$ with collagenase type II from Clostridium histolyticum
(10 $\mathrm{mg} / \mathrm{ml})$, dispase $(60 \mu \mathrm{g} / \mathrm{ml})$ and DNase I $(10 \mu \mathrm{g} / \mathrm{mL}$, all purchased from Sigma). Tissue debris was filtered through a cell strainer. Cells were collected $(900 \times \mathrm{g}$ for $5 \mathrm{~min})$, purified by density gradient centrifugation through Ficoll-Hypaque (Sigma) and immediately stained for flow cytometry analysis or cultured for $16 \mathrm{~h}$ at $37^{\circ} \mathrm{C}$ with or without UV-inactivated HSV-1.

\section{Flow Cytometry Analysis}

Macrophages and lymphocytes $\left(10^{6} / \mathrm{mL}\right)$ freshly dissociated as above described were incubated for $20 \mathrm{~min}$ in PBS containing $2 \% \mathrm{w} / \mathrm{v}$ bovine serum albumin and stained for $30 \mathrm{~min}$ at $4^{\circ} \mathrm{C}$ with proper antibodies (Table 1). For intracellular cytokine staining, cells were subsequently incubated for $30 \mathrm{~min}$ at room temperature in fixation/permeabilization buffer (eBioscience, Italy) containing the proper antibody. Cells were then washed, and fluorescent signal was recorded using BD FACSCanto ${ }^{\text {TM }}$ Flow Cytometry (BD Bioscience, Italy). The results were analyzed using the WinMDI 2.9 (Windows Multiple Document Interface for Flow Cytometry) program.

\section{Detection of Intracellular Free Radicals}

Macrophages $\left(10^{6} / \mathrm{mL}\right)$ freshly dissociated from LMMP as above described were loaded for $30 \mathrm{~min}$ at $37^{\circ} \mathrm{C}$ with $10 \mu \mathrm{M} 2^{\prime}, 7^{\prime}$ dichlorodihydrofluorescein diacetate $\left(\mathrm{H}_{2}\right.$ DCFDA; Molecular Probes, Italy) to detect intracellular ROS or with $5 \mu \mathrm{M} 4,5$ diaminofluorescein (DAF-FM) diacetate (Molecular Probes) to reveal intracellular NO. At the end of incubation, cells were washed twice, stained with the proper antibodies, and analyzed by flow cytometry.

\section{CCL2 Detection by ELISA}

LMMP were homogenized in PBS (1:10 wt/vol) supplemented with protease inhibitors $(1 \mathrm{mmol} / \mathrm{L}$ phenylmethylsulfonyl fluoride, $10 \mu \mathrm{g} / \mathrm{mL}$ aprotinin, $10 \mu \mathrm{g} / \mathrm{mL}$ leupeptin) and centrifuged $\left(10,000 \times \mathrm{g}, 10 \mathrm{~min}\right.$ at $\left.4^{\circ} \mathrm{C}\right)$. Clarified supernatant was assessed for CCL2 protein levels using commercially available kit (eBioscience), following manufacturer's protocol. Optical densities were registered at $450 \mathrm{~nm}$ using a microplate reader (Sunrise, Tecan; Switzerland). The sensitivity of the assay was $15 \mathrm{pg} / \mathrm{ml}$.

\section{Statistical Analysis}

Results were given as mean \pm SEM, except for distribution of the fluorescent probe in in vivo gastrointestinal transit, which was presented as median \pm SEM. Differences in the mean for the different experimental groups was tested using one-way ANOVA analysis followed by Bonferroni multicomparison post-hoc tests. The levels of statistical significance are shown in figure legends. A $P$-value of 0.05 or less was considered statistical significant. Statistical analyses were performed using GraphPad Prism 3.03 software (GraphPad, San Diego, CA). 


\section{RESULTS}

\section{HSV-1 Infects Neurons of the Enteric Nervous System}

In a previous study (Brun et al., 2010) we reported that HSV1 establishes a latent infection in the myenteric ganglia of rats. Indeed, following intragastric inoculation of HSV-1, we found latency-associated and early viral gene transcripts in neurons of the ileum but no expression of late viral genes, suggesting an abortive replication of HSV-1. Despite the ease at which neurons can be studied in rats, the animal model has many limitations including species-specific reagents. Therefore, we moved to develop a murine model of HSV-1 infection of the ENS.

We first ascertained the ability of HSV-1 to retain infectivity following the IG inoculum. Mice were inoculated IG with HSV-1 strain SC16 or equal volume of Vero cell lysate (sham infection) and the ileum content was recovered after 15 and $45 \mathrm{~min}$, vigorously mixed, and centrifuged. The clarified supernatants were incubated on Vero cell monolayers. As reported in Figure 1, contents of ileum collected 15 and 45 min post IG viral inoculum revealed respectively 1 and $10 \%$ of injected PFU as demonstrated by the classical plaque titration assays (Figure 1A). The presence of HSV-1 in Vero cells was confirmed by semi-quantitative PCR analysis (Figure 1B). Samples obtained from mice subjected to sham infection did not produce cytopathic effects on Vero cells.

To demonstrate the ability of HSV-1 strain SC16 to infect murine enteric neurons, cultured primary murine enteric neurons were infected with HSV-1 strain SC16 (MOI 1:1). Cells were fixed $36 \mathrm{~h}$ later and then stained with anti-ICP-27 antibody. As shown in Figure 1C, ICP-27 immunoreactivity is evident in $\beta$ III-tubulin positive neurons, thus confirming the ability of HSV-1 to infect and replicate in mouse enteric neurons.

In the attempt to define the nature of HSV-1 infection in the murine myenteric plexus, we isolated total RNA from LMMP preparations of IG infected mice. HSV-1 latency-associated transcripts (LATs) and mRNA transcripts of the early gene ICP4 were detected to varying extents in the LMMP of animals at 1, 2 , and 3 weeks after IG administration but were undetectable in mice inoculated with Vero cell lysate (sham infection; Figure 1D). HSV-1 thymidine kinase (tk) mRNA were evident in the LMMP only at 2 and 3 weeks post-IG inoculum (Figure 1D). Since we did not observe expression for late genes (VP16, gB, gC) or VP16, gD, and gC proteins (data not shown) we concluded that HSV-1 persistently infected the murine myenteric plexus and carried on an abortive viral replication, as previously reported in the rat model (Brun et al., 2010).

\section{Orogastric HSV-1 Inoculum Causes Intestinal Dysmotility in Mice}

Infection with HSV-1 strain 16 or replication-defective mutants did not produce signs of central or peripheral neurological deficit in mice (data not shown) but resulted in time-dependent motility anomalies in different intestinal segments. IG inoculum of HSV1 strain SC16 caused faster gastric emptying, delayed intestinal transit and slower colonic motility as compared to sham infected animals (Figures 2A-C). The intestinal neuromuscular contractility was transiently impaired. Thus, electrical field stimulation (EFS)-elicited contractions in isolated segments of ileum was significantly reduced at the first week of infection compared to those from sham infected mice and was almost completely restored at the second and third week post-infection (Figure 2D). No alterations in gastrointestinal transit and EFSinduced contractility were detected in sham infected mice.

\section{HSV-1 Infection Causes Neuroplastic Changes of the ENS}

The functional studies revealed compromised gastrointestinal motor function. Since the ENS controls intestinal motility we next evaluated the integrity of the neuroglial network in the gut wall of mice subjected to IG HSV-1 inoculum. Although the histological examination of HSV-1 infected mice revealed conserved architecture in the small intestine (Figure 3A), immunofluorescence studies on whole mount preparations of LMMP demonstrated abnormalities in neurons and glial cells (Figures 3B-D). Immunoreactivity of the glial marker S$100 \beta$, a $\mathrm{Ca}^{2+}$-modulated protein implicated in intracellular and extracellular regulatory activities, was increased mainly at the second and third week post-IG HSV-1 inoculum (Figure 3B), indicating activation of enteric glial cells. Though immunoreactivity of peripherin and $\beta$ III-tubulin enhanced 1-week post-IG HSV inoculum, the structural integrity of neurofilaments was overall preserved (Figure 3B). However, the neurochemical code in the ENS significantly changed following HSV-1 infection. Neuronal nitric oxide synthase (nNOS) protein expression increased in the LMMP of HSV-1 infected mice. Expression of choline acetyltransferase (ChAT) decreased 1-week post-HSV-1 inoculum but regained levels comparable with sham infected mice at later time points (Figures 3C,D). Considering the impact of nitric oxide as inhibitory neurotransmitter on intestine, we then verified the functional consequences of increased nNOS expression in the myenteric plexus of HSV-1 infected mice. In agreement with previous reports (Serio et al., 2003), at 1-week post-infection non-adrenergic, non-cholinergic evoked relaxation in explants of ileum was abolished by the NOS inhibitor $\mathrm{N}_{\omega}$-Nitro-L-arginine methyl ester hydrochloride (L-NAME), indicating its nitrergic origin (Figure 3E). Thus, the increased expression of nNOS in the myenteric plexus of HSV-1 infected mice amplified the nitrergic effect in intestinal contractility, accounting for the delayed gastrointestinal transit (see Figure 2B). Altogether these data support the view that, following IG inoculum, HSV-1 induces neuroplastic changes in neuronal circuits of the gut leading to dysmotility.

\section{Gastrointestinal Neuromuscular Dysfunctions Are Independent of Viral Replication}

To dissect the factors responsible for ENS neuroplasticity and gastrointestinal dysmotility, we first verified whether HSV-1 replication is mandatory for the onset of neuronal alterations. Mice were infected with two engineered HSV-1 strains deleted of immediate early genes essential to initiate viral replication (Marconi et al., 2010). As shown in Figures 4A-C, the IG inoculum with replication-defective HSV-1 IGR20 $\triangle$ ICP27gJHE 
A

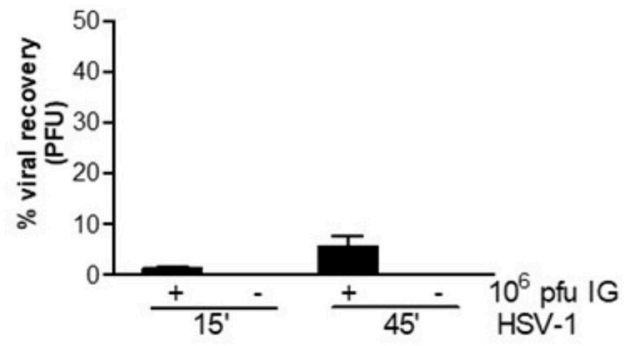

C

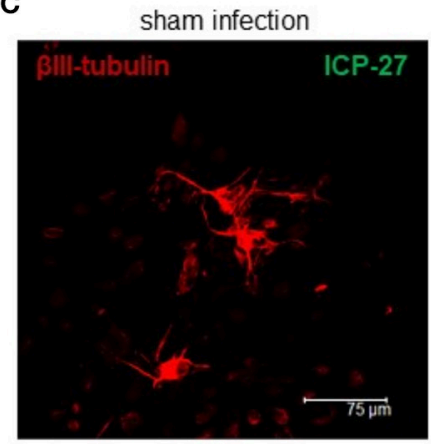

B

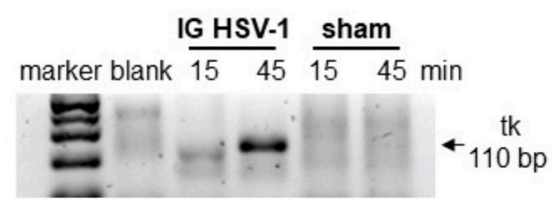

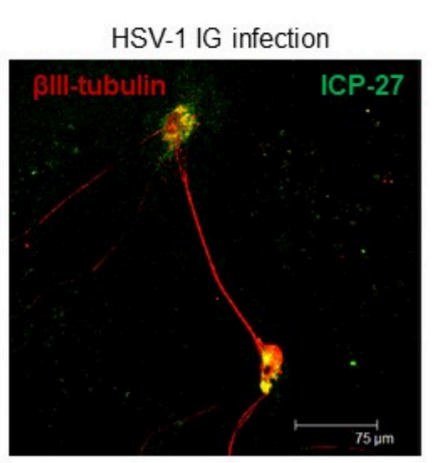

D

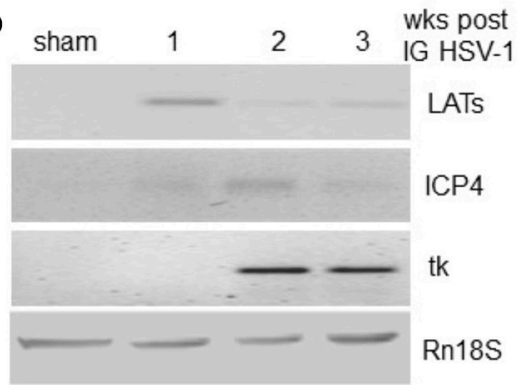

FIGURE 1 | HSV-1 infection of the ENS. (A) The content of the ileum was collected from mice at 15 and 45 min post-IG inoculum with HSV-1 strain 16 ( $1 \times 10^{7}$ PFU). Intestinal content was co-cultured on Vero cells and plaques were counted. The number of plaques derived from Vero cells incubated with HSV-1 strain SC16 $(1 \times$ $10^{7} \mathrm{PFU}$ ) but not injected in mice was taken as $100 \%$. Data are represented as mean \pm SEM of three separated experiments. $n=4$ mice per group. (B) Total DNA was isolated from Vero cells exposed for up to $72 \mathrm{~h}$ to content of ileum obtained from mice inoculated IG with HSV-1 or sham infected. DNA was subjected to PCR using HSV-1 tk specific primers. Representative picture of one out of three agarose gel is reported. bp: base pairs. (C) Primary enteric neurons were infected with HSV-1, fixed $36 \mathrm{~h}$ later, and probed with anti- $\beta$-III-tubulin (red) and anti-ICP-27 (green) antibodies. Cells were imaged using a confocal microscope. Representative images are shown. (D) One, two, and three weeks post-IG inoculum of HSV-1 strain SC16, total RNA was purified from LMMP and semi-quantitative PCR was performed to evaluate the expression of HSV-1 LATs and early (ICP4, tk) mRNA transcripts. A representative experiment is shown. Rn18S was used as extraction and loading control. Sham: mice IG inoculated with Vero cell lysate.

$\left(\mathrm{ICP} 27^{-/-}\right)$induced gastrointestinal contractile dysfunctions resembling those observed following infection with HSV-1 strain SC16 and reported in Figure 2. At the same time, the replicationdefective virus caused structural abnormalities of the ENS (Figure 4D). Infection with the other replication-defective HSV1, T0Z AICP4.ICP27.ICP22.UL41 (Krisky et al., 1998), caused similar functional and structural anomalies of the ENS (data not shown). These data indicate that the neuromuscular dysfunctions observed following IG HSV-1 inoculum are not merely due to viral replication, but most likely result from host-mediated immune mechanisms.

\section{Adaptive Immune Responses Do Not Contribute to Intestinal Neuromuscular Dysfunction}

To investigate the role of immune cell activation on gastrointestinal neuromuscular dysfunctions we at first examined lymphocyte recruitment. Four weeks following IN HSV-1 inoculum, circulating anti-HSV-1 IgG and HSV-1 reactive spleen $\mathrm{CD}^{+}$lymphocytes were evident (data not shown). However, in the LMMP, the distribution and percentage of $\mathrm{CD}^{+}$cells, the $\mathrm{CD}^{+}: \mathrm{CD}^{+}$ratio, and the percentage of $\mathrm{CD} 3{ }^{+} \mathrm{CD} 8^{+} \mathrm{IFN} \gamma^{+}$cells were unaffected by IG HSV-1 inoculum
(Figures 5A-D,F). HSV-1 responsive $\mathrm{CD}^{+} \mathrm{CD} 4^{+} \mathrm{IL}^{+}{ }^{+}$cells were revealed at the second week following IG HSV-1 inoculum (Figures 5E,G). Moreover, the percentage of $\mathrm{CD}^{-} \mathrm{CD}^{-} 9^{+} \mathrm{B}$ lymphocytes and $\mathrm{CD}^{-} \mathrm{NK} 1.1^{+} \mathrm{NK} \mathrm{T}$ cells did not change following IG HSV-1 inoculum as compared with sham infected mice (data not shown).

To ascertain the role of HSV- 1 activated $\mathrm{CD}^{+}{ }^{+} \mathrm{CD} 4^{+}$cells on gastrointestinal neuromuscular dysfunctions, infected mice received an intraperitoneal bolus of monoclonal anti-CD4 antibody 1 day following IG HSV-1 administration and were sacrificed at the second week post-IG infection. Depletion of $\mathrm{CD}^{+}{ }^{+}$cells did not correct the gastrointestinal and colonic dysmotility (Figures 5 $\mathbf{H}, \mathbf{J}$ ) suggesting that the HSV-1-driven $\mathrm{CD} 3^{+} \mathrm{CD} 4{ }^{+}$cells recruitment in the LMMP does not account for the observed gastrointestinal neuromuscular dysfunctions.

\section{Macrophages Infiltrating the LMMP Damage the ENS}

We next investigated the role of the innate immunity in HSV-1 induced gastrointestinal dysmotility focusing on macrophages, cells controlling early phases of HSV-1 infection (Kodukula et al., 1999). Gut macrophages were studied by flow cytometry analysis on cells isolated from LMMP 

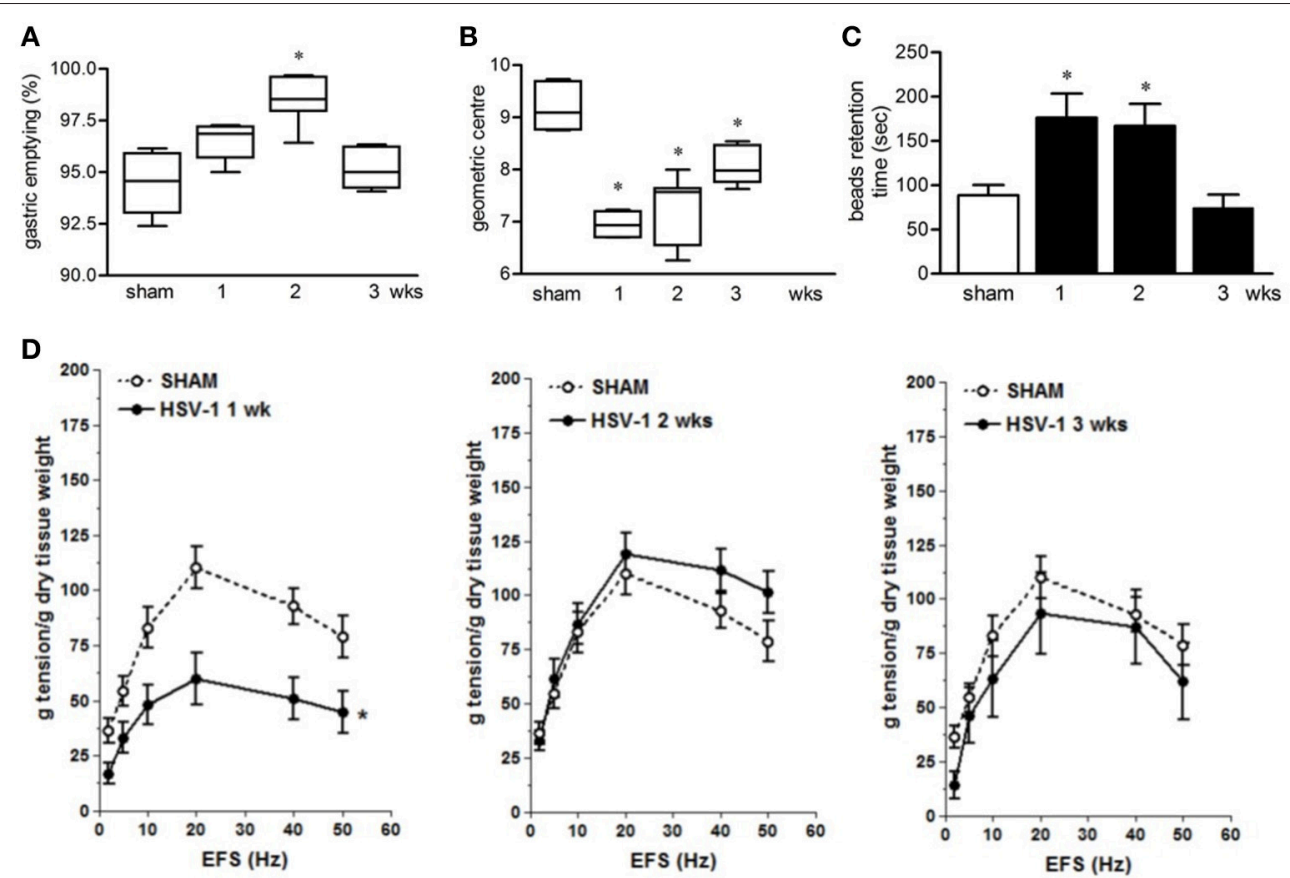

FIGURE 2 | Gastrointestinal dysmotility in HSV-1 infected mice. (A) One, two, and three weeks post-IG infection with replicating HSV-1 strain SC16, mice were injected with non-absorbable FITC-labeled dextran. Sixty minutes later mice were sacrificed. Gastric emptying was calculated as the percentage of probe retained into the stomach compared with the total amount of fluorescence in the gastrointestinal tract. (B) Distribution of FITC-labeled dextran was determined in the intestine. Intestinal transit was reported as the geometric center of distribution of the fluorescent probe throughout the ileum. (C) Time (seconds, sec) required for expulsion of a glass bead inserted into the rectum. (D) Electrical field stimulation (EFS)-elicited contractions in segments of ileum from sham and IG HSV-1 infected mice. Data are represented as mean \pm SEM. $n=6-12$ mice per group. *Denotes $P<0.01$ compared to sham infected mice.

and characterized as $\mathrm{CD} 11 \mathrm{~b}^{+} \mathrm{F} 4 / 80^{+}$cells. As reported in Figures 6A-D, CD $11 \mathrm{~b}^{+} \mathrm{F} 4 / 80^{+}$cells were barely detectable in the LMMP of sham infected mice. Starting the first week following the IG inoculum of HSV-1 strain 16, significant increase in $\mathrm{CD} 11 \mathrm{~b}^{+} \mathrm{F} 4 / 80^{+}$macrophages was observed (Figures 6A,C). Immunohistochemistry on sections of the ileum revealed $\mathrm{CD}_{11 \mathrm{~b}}{ }^{+}$cells contiguous to the myenteric ganglia following IG viral inoculum (Figures 6B,D).

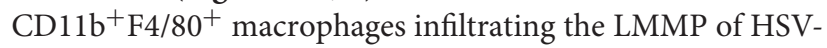
1 infected mice exhibited an activated phenotype since they generated free radicals, namely reactive oxygen species (ROS) and nitric oxide (NO; Figures 6E,F).

Taking into consideration also the data reported in Figure 3, to establish the role of macrophage-derived $\mathrm{NO}$ in functional alterations of the ENS, we administered HSV-1 infected mice with L-NAME, a non-selective NOS inhibitor. At 1-week postHSV-1 infection, L-NAME administration ameliorated intestinal motility (Figure 6G). At the same, treatment with selective iNOS inhibitor, namely AR-C102222, significantly improved HSV-1 associated intestinal dysmotility (Figure 6G). No effects were observed in mice treated with vehicle alone (data not shown).

To ascertain the contribution of infiltrating macrophages on gastrointestinal neuromuscular dysfunction, circulating monocytes and tissue macrophages were depleted by intraperitoneal injection of clodronate-containing liposomes (Clodrolip) (Zeisberger et al., 2006). As shown in Figures 7A,B
Clodrolip injection was effective at depleting $\mathrm{CD} 11 \mathrm{~b}^{+} \mathrm{F} 4 / 80^{+}$ cells in LMMP when compared with empty liposome-injected mice. Macrophage depletion by Clodrolip did not alter histological appearance of intestine (Figure 7C) and almost completely restored gastrointestinal motility in HSV-1 infected mice in term of intestinal transit, colonic motility, and EFSelicited contractions in ileum (Figure 7D-F). HSV-1 induced structural anomalies of the ENS ameliorated in Clodrolip-treated mice (Figure 7G).

\section{MCP-1 Mediates Macrophage Recruitment in the LMMP of HSV-1 Infected Mice}

Since monocyte chemoattractant protein-1 (MCP-1/CCL2) and its receptor CCR2 have been demonstrated to be involved in macrophage-dependent tissue damage (Gosling et al., 1999; Huang et al., 2001), we wondered whether the CCL2/CCR2 pathway was involved also in the HSV-1-induced damage of the ENS. CCL2 levels significantly increased in the LMMP following IG HSV-1 inoculum as determined by ELISA and quantitative RT-PCR (Figures 8A,B). In addition, Ccr2 mRNA levels were induced by HSV-1 infection (Figure 8C). Immunohistochemistry on sections of ileum revealed CCL2 positive cells located only in the mucosa of sham infected mice whereas 1 week following HSV-1 infection, CCL2 positive cells were detectable inside the myenteric ganglia (Figure 8D). In the attempt to identify the major source 
A

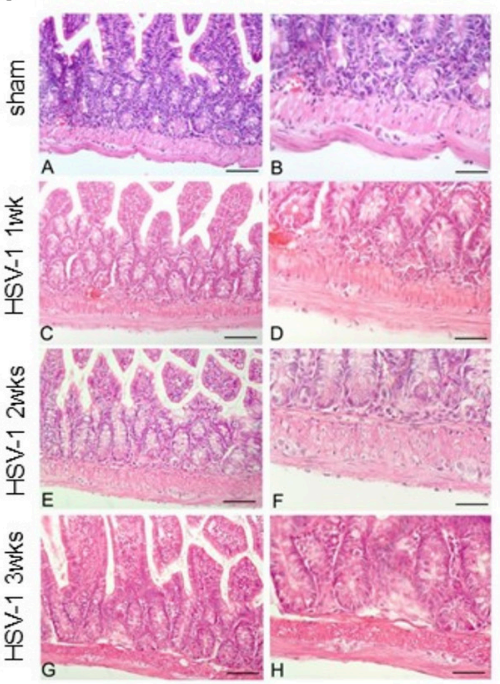

C
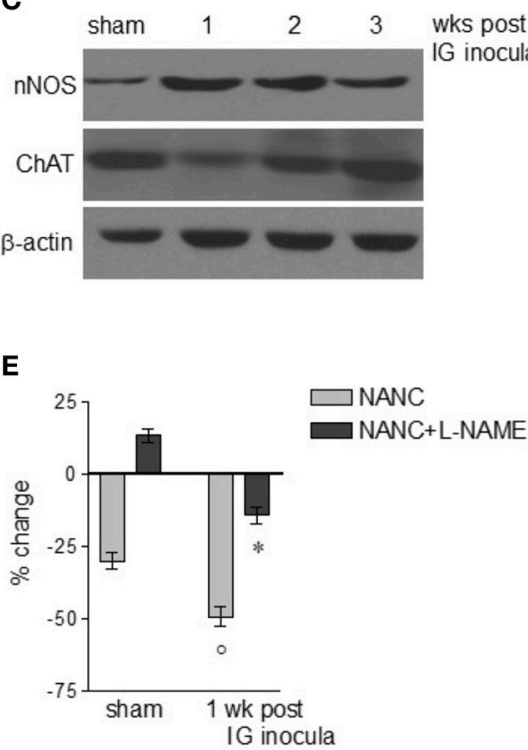
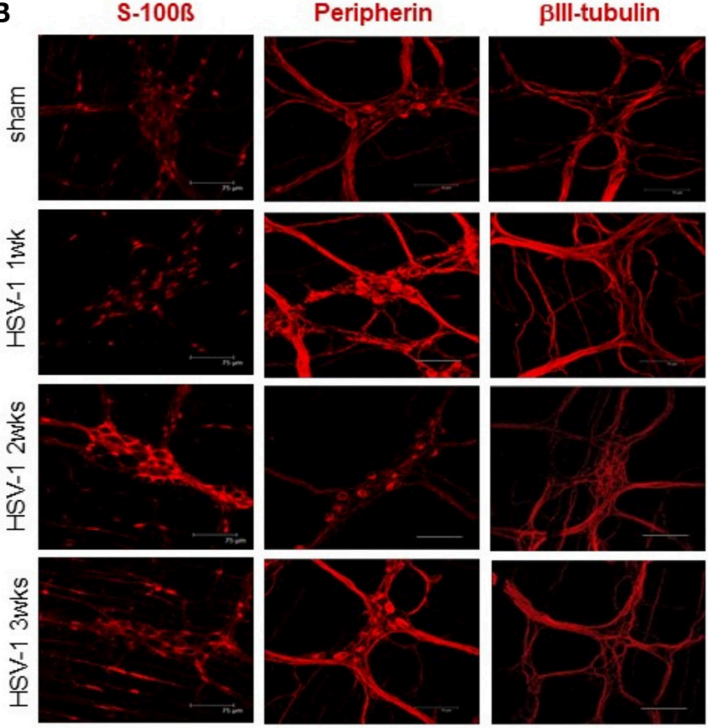

\section{D}
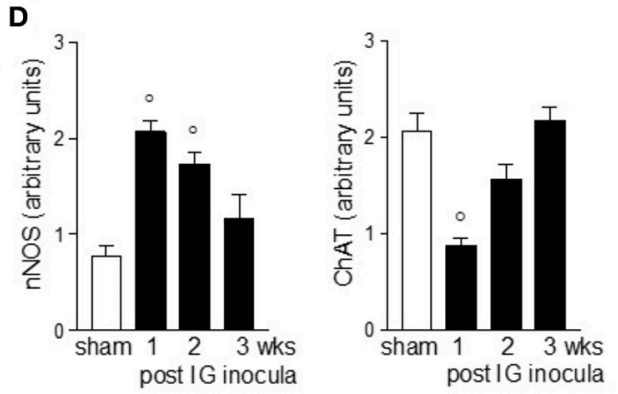

FIGURE 3 | Alterations in myenteric plexus during HSV-1 infection. (A) One, two, and three weeks post-IG infection with HSV-1 strain SC16, distal ileum was removed and fixed in neutral buffered formalin, embedded in paraffin, and subjected to H\&E staining. Representative images are presented. Scale bars: $40 \mu \mathrm{m}$ in (left panels); $20 \mu \mathrm{m}$ in (right panels). (B) Samples of distal ileum were fixed to obtain whole mount preparations. Immunofluorescence analysis for S-100 $\beta$ (glial marker), neurofilament peripherin, and neurotubules $\beta$ III-tubulin was performed. Scale bars: $75 \mu \mathrm{m}$. Representative images of three separate experiments. (C) Western Blot analysis of nNOS and ChAT in protein extracts from LMMP of sham and IG HSV-1 infected mice. $\beta$-actin was used as loading control. Images representative of three different blots with similar results are reported. (D) Protein signals were quantified using ImageJ and reported as arbitrary units. (E) Non-adrenergic, non-cholinergic (NANC) responses of segments of ileum obtained from sham and 1-week HSV-1 infected mice evoked by EFS in absence or presence of L-NAME. Percent change is expressed as change in grams of active tension before EFS-induced relaxation. Data are represented as mean \pm SEM of at least two separate experiments. ${ }^{\circ}$ Denotes $P<0.05$ compared to sham infected mice. *Denotes $P<0.02$ compared to mice at 1 week of infection in absence of L-NAME.

of CCL2 in the LMMP during HSV-1 infection, cultured enteric neurons were incubated with UV-inactivated HSV-1. Immunostaining demonstrated increased CCL2 in enteric neurons $16 \mathrm{~h}$ post-exposure to $\mathrm{HSV}-1$ antigens (Figure 8E). To prove the functional role of the CCL2/CCR2 pathway on HSV-1 induced gastrointestinal dysmotility, HSV-1 infected mice were treated with RS504393, a highly selective CCR2 chemokine receptor antagonist (Kitagawa et al., 2004). Immunohistochemistry for $\mathrm{CD} 1 \mathrm{~b}^{+}$cells in sections of ileum from HSV-1 infected mice treated with RS504393 proved a drastic reduction in macrophage recruitment (Figure 8F). Most interestingly, RS504393 treatment prevented the occurrence 

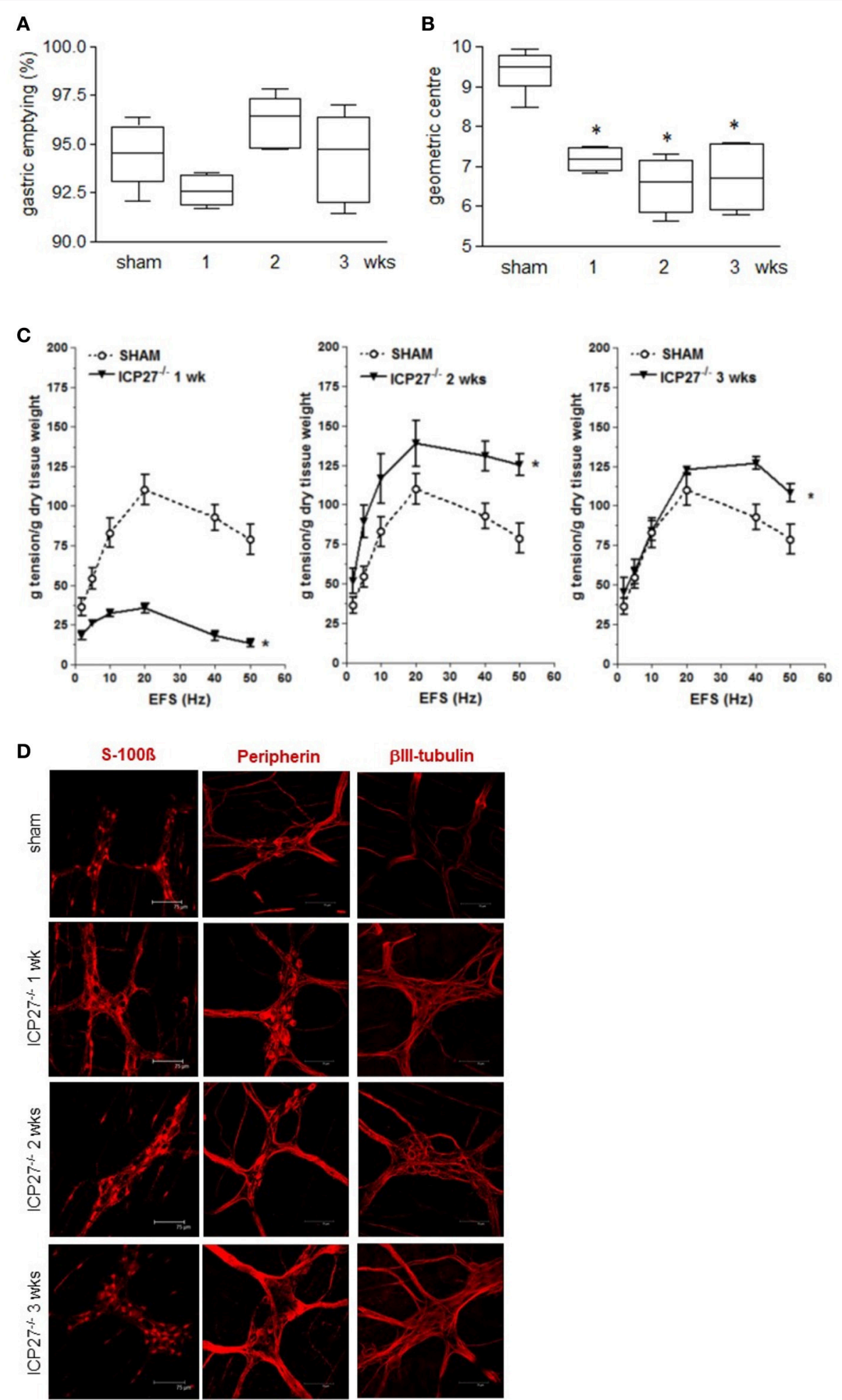

FIGURE 4 | Persistence of gastrointestinal alterations in mice infected with HSV-1 replication-defective strain (A) Mice were injected IG with HSV-1 IGR20 $\triangle \mathrm{ICP} 27 \mathrm{gJHE}\left(\mathrm{ICP} 27^{-/-}\right)$replication-defective strain. Mice received non-absorbable FITC-labeled dextran 1, 2, and 3 weeks post-IG inocula. Sixty minutes later mice were sacrificed, and gastric emptying was calculated as the percentage of probe retained into the stomach compared with the total amount of fluorescence in the gastrointestinal tract. (B) Distribution of FITC-labeled dextran was determined in the intestine. Intestinal transit was reported as the geometric center of distribution of the fluorescent probe throughout the ileum. (C) EFS-elicited contractions in segments of ileum of sham and IG HSV-1 ICP27-/- infected mice. Data are represented as mean \pm SEM. $n=6$ mice per group. *Denotes $P<0.01$ compared to sham infected mice. (D) Immunofluorescence analysis for $S-100 \beta$, peripherin, and $\beta I I I-t u b u l i n$ on whole mount preparations of ileum of HSV-1 ICP27-/- infected mice. Scale bars: $75 \mu \mathrm{m}$. Representative images of three separate experiments. 


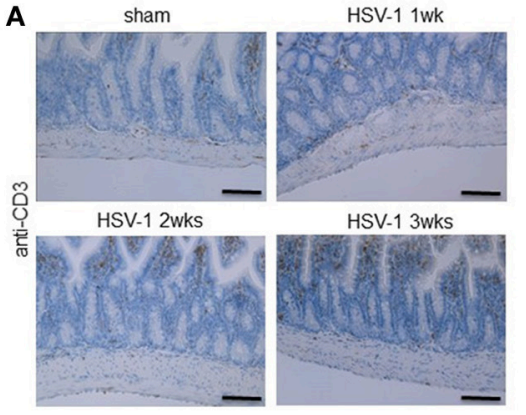

D $\mathrm{CD}^{+}$cells
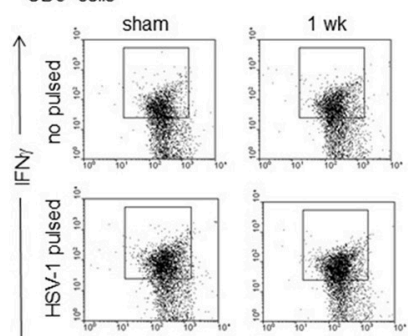

$\mathrm{CD} 8$
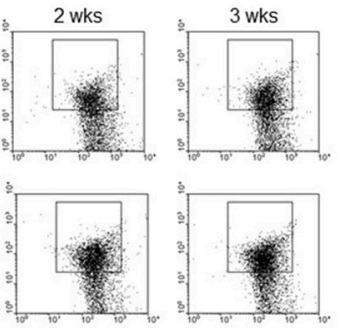

E

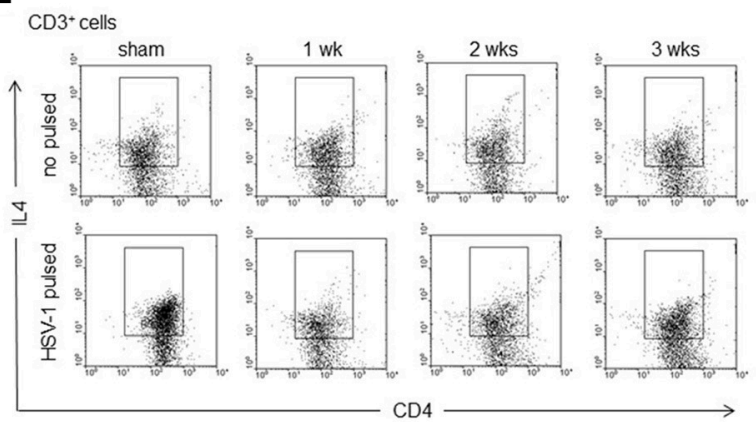

CD4
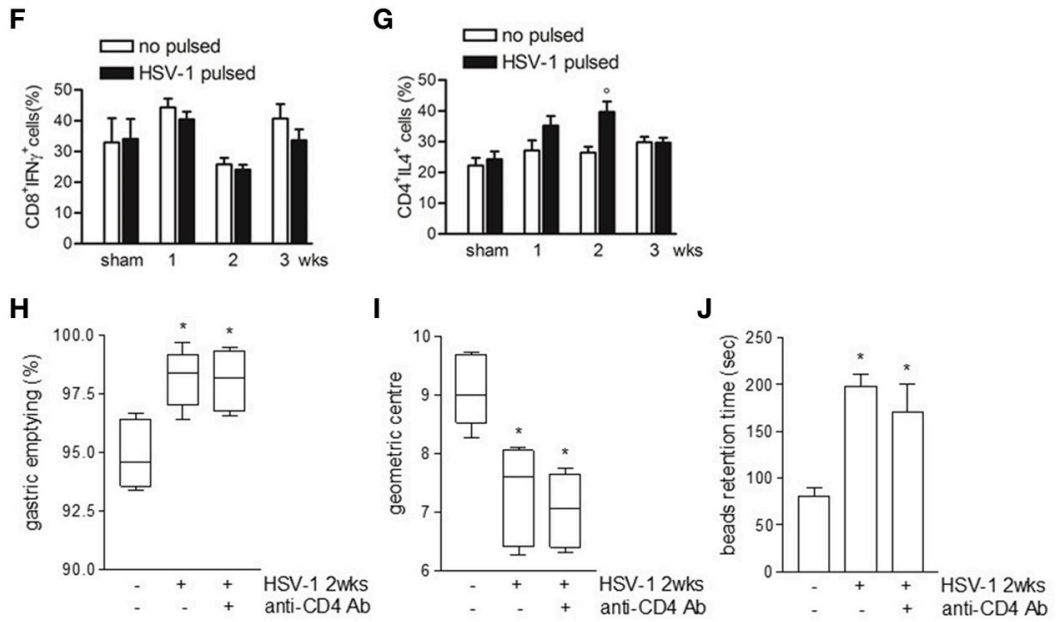

FIGURE 5 | Weak adaptive immune response in the LMMP following HSV-1 administration. (A) Sections of ileum obtained from sham or HSV-1 strain SC16 infected mice were subjected to immunohistochemistry for CD3. Scale bars: $40 \mu \mathrm{m}$. Representative images of three separate experiments. (B) Freshly collected LMMP were digested and the resulting cell suspension were labeled with anti-CD3 antibody and analyzed by flow cytometry. $\mathrm{CD}^{+}$cells were expressed as percentage of $10^{5}$ collected events. (C) Cell suspensions obtained from LMMP as previously described were labeled with anti-CD3, anti-CD4 or anti-CD8 antibodies and analyzed by flow cytometry. CD4:CD8 ratio of $1 \times 10^{5} \mathrm{CD}^{+}$cells was calculated. $(\mathbf{D}, \mathbf{E})$ Cell suspensions obtained from LMMP were incubated for $16 \mathrm{~h}$ in presence or absence (Continued) 
FIGURE 5 | of UV-inactivated HSV-1 strain SC16. Cells were then collected, labeled with anti-CD3, anti-CD8 and anti-IFN $\gamma$ or anti-CD3, anti-CD4 and anti-IL4 antibodies and analyzed by flow cytometry in $5 \times 10^{4}$ collected events. Representative images of at least five separate experiments are reported. (F,G) Percentages of fluorescence as reported in (D,E) were graphed. $N=5$ mice per group. ${ }^{\circ}$ Denotes $P<0.05$ compared to no HSV-1 pulsed cells at the same time point. (H) Mice infected with HSV-1 strain 16 were intraperitoneally injected with rat anti-mouse CD4 purified monoclonal antibody (anti-CD4 Ab). Two weeks post-IG infection, mice received IG non-absorbable FITC-labeled dextran. Sixty minutes later mice were sacrificed. Gastric emptying was calculated as the percentage of probe retained into the stomach compared with the total amount of fluorescence in the gastrointestinal tract. (I) Distribution of FITC-labeled dextran was determined in the intestine. Intestinal transit was reported as the geometric center of distribution of the fluorescent probe throughout the ileum. (J) Time (seconds, sec) required for expulsion of a glass bead inserted into the rectum. Data are represented as mean \pm SEM. $n=6-9$ mice per group. *Denotes $P<0.05$ compared to sham infected mice.

of HSV-1-induced gastrointestinal neuromuscular dysfunction (Figures 8G,H).

\section{DISCUSSION}

Functional gastrointestinal disorders are ascribed either directly or indirectly to altered activity of the ENS. Although degenerative neuropathy and intestinal dysmotility have been reported in patients suffering from irritable bowel syndrome (IBS) (Törnblom et al., 2002; Lindberg et al., 2009), the etiology and underlying pathophysiologic mechanisms remain largely unknown. Recently, Muller et al. found a tight communication between enteric neurons and resident gut macrophages under steady state conditions (Muller et al., 2014), arising the hypothesis that any inflammatory insult might perturb the function of neuronal network and vice versa neuronal damage might intensify gut inflammation. In the present study, we reported that following IG inoculum in mice, the neurotropic virus HSV-1 eludes the gastric barrier, reaches the gut lumen, and persists in enteric neurons (Figure 1). Through secretion of CCL2, infected neurons guide the recruitment and activation of macrophages which, via NO production, are responsible for the neuromuscular dysfunction (Figures 7, 8). Since HSV-1 DNA is intermittently shed in the saliva of even asymptomatic subjects and recovered in feces (Buddingh et al., 1953; Kaufman et al., 2005), these findings support the role of HSV-1 and viral-induced inflammation in gastrointestinal motor disorders.

Besides the classical antibacterial role, gut macrophages are devoted to maintaining the integrity of the enteric neurons, as also described in the central nervous system (Ginhoux et al., 2010; Cipriani et al., 2016). As opposed to the brain, macrophages at the interface between the host and the luminal environment are exposed to multiple factors and activate to clear dangerous agents or to recruit additional inflammatory cells (Phillips and Powley, 2012; Cipriani et al., 2016). Indeed, activated macrophages play an important part in the pathogenesis of intestinal dysfunctions both during experimentally induced inflammatory conditions (Galeazzi et al., 2001) and in presence of infectious agents (Kurt-Jones et al., 2004; Ellermann-Eriksen, 2005; Koyuncu et al., 2013). Inflammatory mediators such as reactive nitrogen and oxygen species (NO, ROS), interleukins and chemoattractant factors released by gut macrophages directly cause neuromuscular dysfunction in surgical manipulated ileum as well as in diabetic gastroparesis (Hurst and Collins, 1994; Khan and Collins, 1994; Wehner et al., 2007). In the present study we demonstated that the LMMP of mice at the early time of HSV-1 infection is infiltrated by activated macrophage, which generate ROS and NO (Figure 6). Depletion of $\mathrm{CD} 11 \mathrm{~b}^{+} \mathrm{F} 4 / 80^{+}$cells by Clodrolip as well as quencing the NO production by administration of NO synthase inhibitors significantly ameliorated neuromuscular dysfunction (Figures 6, 7) highlighting the key role of oxidative damage in enteric motorneuronal injuries. Indeed, NO directly or through peroxynitrite formation and tyrosine nitrosylation is involved in DNA damage and protein misfolding thus contributing to neurodegeneration and neuromuscular dysfunction (Nakamura et al., 2015). The ability of HSV-1 to establish a latent/abortive infection in enteric neurons, to induce an inflammatory response in the LMMP, and to alter the gastrointestinal motility has been previously reported in rats (Brun et al., 2010), thus confirming in two different animal models the involvement of HSV-1 in structural and functional alterations of peripheral nervous system. The amplitude and the functional consequences of HSV1 infection of the ENS are however different in mice and rats probably because the differences in the subnetworks of chemokines and cytokines described in the two animal models (Du et al., 2017) that differently impact in the neuroplasticity of the ENS.

In the current study, we observed that following HSV1 intragastrical inoculum the ENS underwent a variety of plastic changes (Figures 2, 3). Indeed, alterations of S100$\beta$ expression, type III intermediate filament peripherin, and the microtubule element $\beta$ III-tubulin (Figure 3B) have been described in several pathological conditions characterized by neuronal sufferance (Liem and Messing, 2009; Tischfield and Engle, 2010; Brun et al., 2013). Moreover, by Western blot analysis we reported increased expression of nNOS in myenteric plexus of HSV-1 infected mice associated with reduced intestinal transit and colonic motility (Figures 2B,C, 3C,D). The increased production of the inhibitory neurotransmitter NO occurs with concomitant reduction in the expression of ChAT at 1 week of infection (Figures 3C,D) when the nerve-mediated contractions (Figure 2D) and nerve coordinated gastrointestinal motility (Figures 2B,C) significantly differ from sham infected mice.

Like gut macrophages, enteric neurons synthesize and release cytokines, chemokines and growth factors to timely recruit and drive inflammatory cell adaptation to environmental perturbations (Coquenlorge et al., 2014; Burgueño et al., 2016; Gabanyi et al., 2016). During viral infection, neuronalderived soluble factors take part in the development of neuroinflammation and fuel the inflammatory-immune circuits leading to tissue damage (Kumar et al., 2010; Chai et al., 2015). Similarly, besides the well-known type I and III interferon antiviral responses (Melchjorsen, 2012), neurons challenged 
A
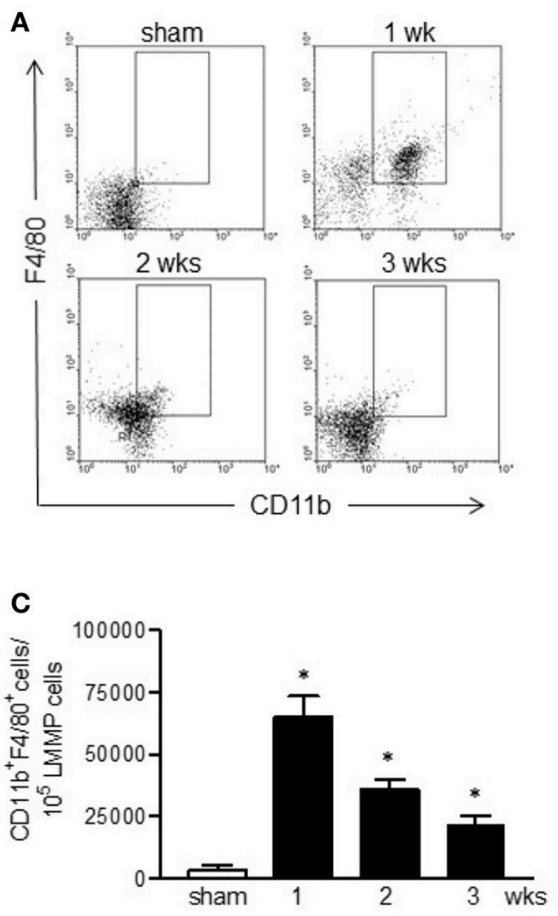

E

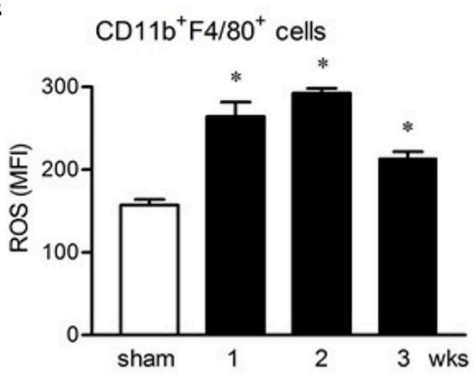

B

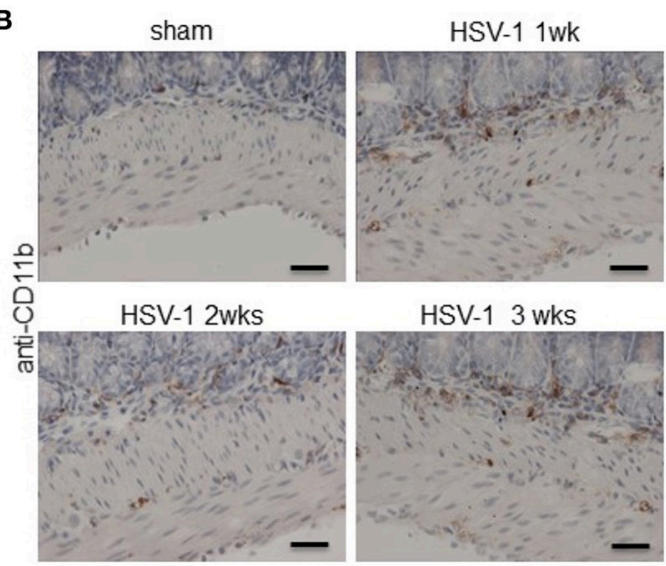

D

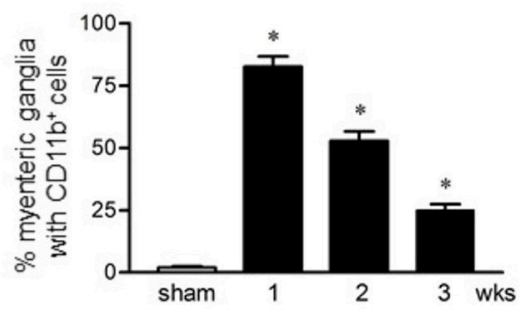

$\mathbf{F}$

CD11b ${ }^{+} \mathrm{F} 4 / 80^{+}$cells

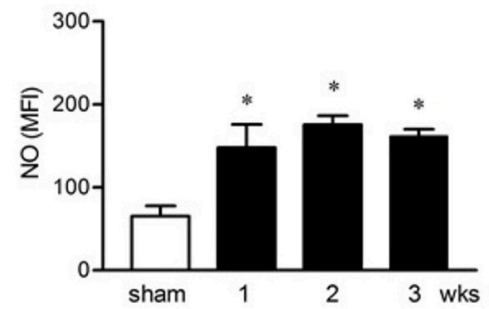

G

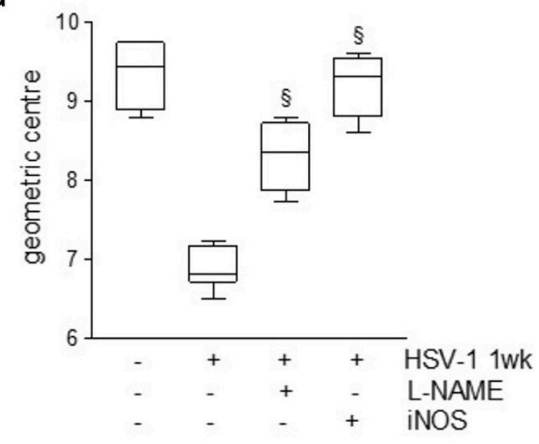

FIGURE 6 | Activated macrophages infiltrate and damage the ENS of HSV-1 infected mice. (A) Freshly collected LMMP were digested and the resulting cell suspensions were labeled with anti-CD11b and anti-F4/80 antibodies and analyzed by flow cytometry. Representative images of five separate experiments. (B) Immunohistochemistry for CD11b on sections of ileum. Representative images of three separate experiments. Scale bars: $40 \mu \mathrm{m}$. (C) CD11 ${ }^{+}$F4/80 ${ }^{+}$cells analyzed by flow cytometry as in (A) were enumerated in $10^{5}$ collected events. (D) Myenteric plexuses reporting juxtaposed CD11 ${ }^{+}$cells as in (B) were counted and normalized to the number of total myenteric plexuses. Data are reported as percentage. (E) Cells obtained from LMMP were incubated for 30 min at $37^{\circ} \mathrm{C}$ with $\mathrm{H}_{2}$ DCFDA, a probe detecting intracellular ROS or (F) with DAF-FM to detect intracellular NO. Cells were then labeled with anti-CD11b and anti-F4/80 antibodies. Mean fluorescent intensity (MFI) was detected by flow cytometry in 10.000 events. $n=3-9$ mice per group. ${ }^{*}$ Denotes $P<0.01$ compared to sham infected mice. (G) Mice infected with HSV-1 strain 16 were intraperitoneally injected with L-NAME, a pan-NOS inhibitor, or with iNOS inhibitor (AR-C102222). At 1-week of infection, mice were administered with non-absorbable FITC-labeled dextran and sacrificed 60 min later. Intestinal transit was reported as the geometric center of distribution of the fluorescent probe throughout the ileum. Data are represented as mean \pm SEM. $n=6$ mice per group. ${ }^{\S}$ Denotes $P<0.05$ compared to 1 -week HSV-1 infected mice. 

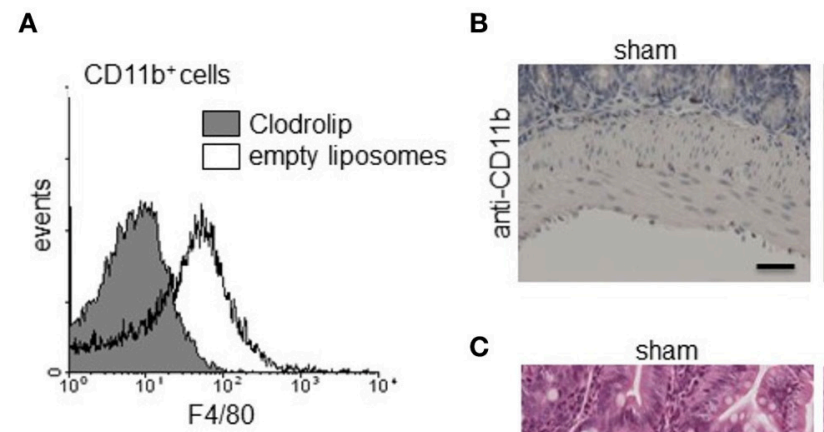

C

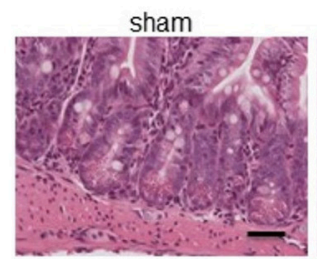

D

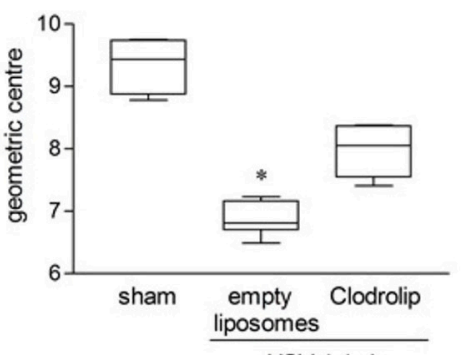

HSV-1 1wk

G

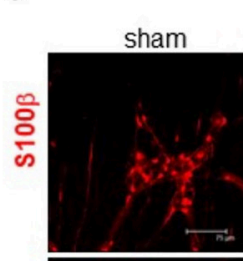

HSV-1 1wk+ empty lyposomes
E

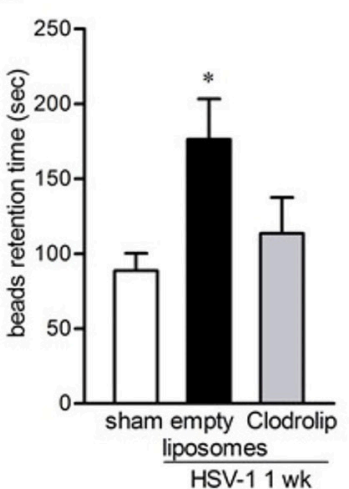

HSV-1 1wk+

\section{Clodrolip}
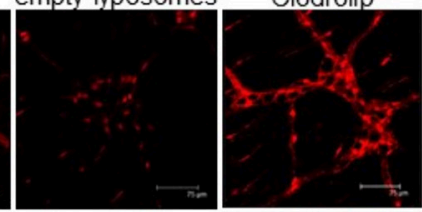

HSV-1 1wk+

empty liposomes

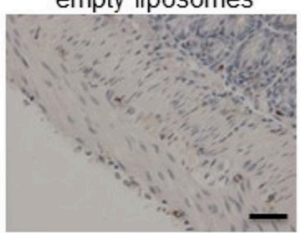

HSV-1 1wk+

empty liposome

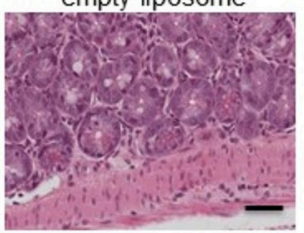

F

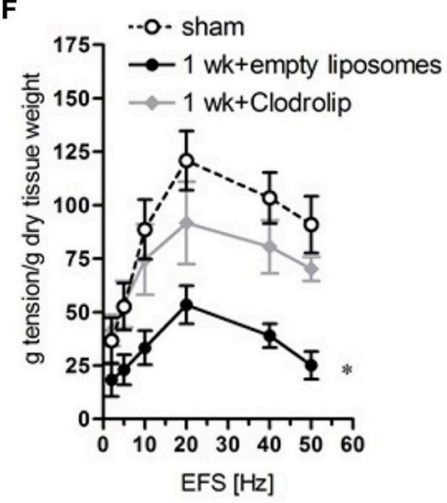

HSV-1 1wk+

Clodrolip

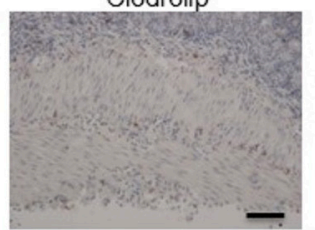

HSV-1 1wk+

Clodrolip

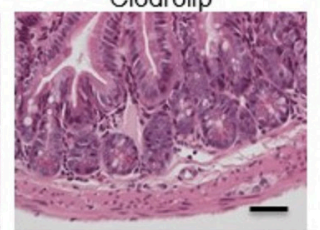

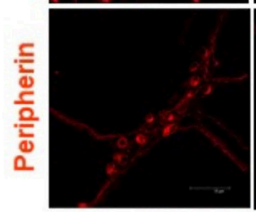
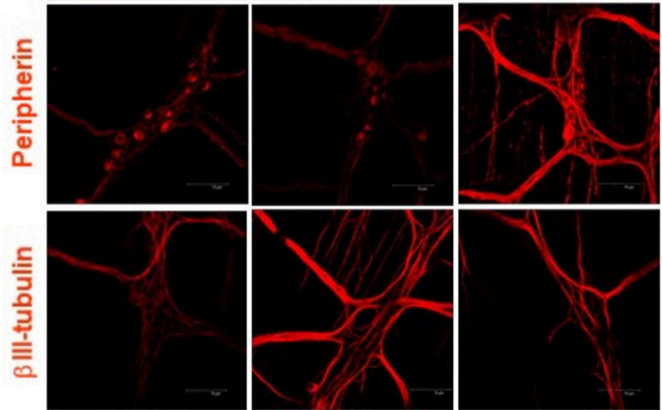

FIGURE 7 | Depletion of macrophage in the LMMP ameliorates HSV-1-induced alterations of the ENS. (A) Cells were isolated form LMMP of 1-week HSV-1 infected mice treated with Clodrolip or empty liposomes as control. To confirm macrophages depletion, F4/80 expression was evaluated by flow cytometry in CD11b ${ }^{+}$cells. (B) Sections of ileum obtained from 1-week HSV-1 infected mice treated with Clodrolip or empty liposomes were subjected to immunohistochemistry for CD11b. Scale bars: $40 \mu \mathrm{m}$. (C) Histological analysis of samples of ileum obtained from 1-week HSV-1 infected mice treated with empty liposomes or Clodrolip. Sections were subjected to H\&E staining. Scale bars: $40 \mu \mathrm{m}$. Images are representative of three separate experiments. (D) At 1-week post-IG HSV-1 inoculum, mice injected with Clodrolip or empty liposomes were administered with non-absorbable FITC-labeled dextran and sacrificed 60 min later. Intestinal transit was reported as the geometric center of distribution of the fluorescent probe throughout the ileum. (E) Time (seconds, sec) required for expulsion of a glass bead inserted into the rectum in Clodrolip or empty liposomes treated mice at 1 week of IG infection. (F) EFS-elicited contractions in segments of ileum obtained from mice at 1 week of IG infection and treated with Clodrolip or empty liposomes. Data are reported as mean \pm SEM. $n=6$ mice per group. *Denotes $P<0.01$ compared to sham infected mice. (G) Immunohistochemistry for S-100 , peripherin, and $\beta$ III-tubulin on whole mount preparations of distal ileum obtained from 1-week HSV-1 infected mice and treated with Clodrolip or empty liposomes. Representative images of three separate experiments. Scale bars: $75 \mu \mathrm{m}$. 

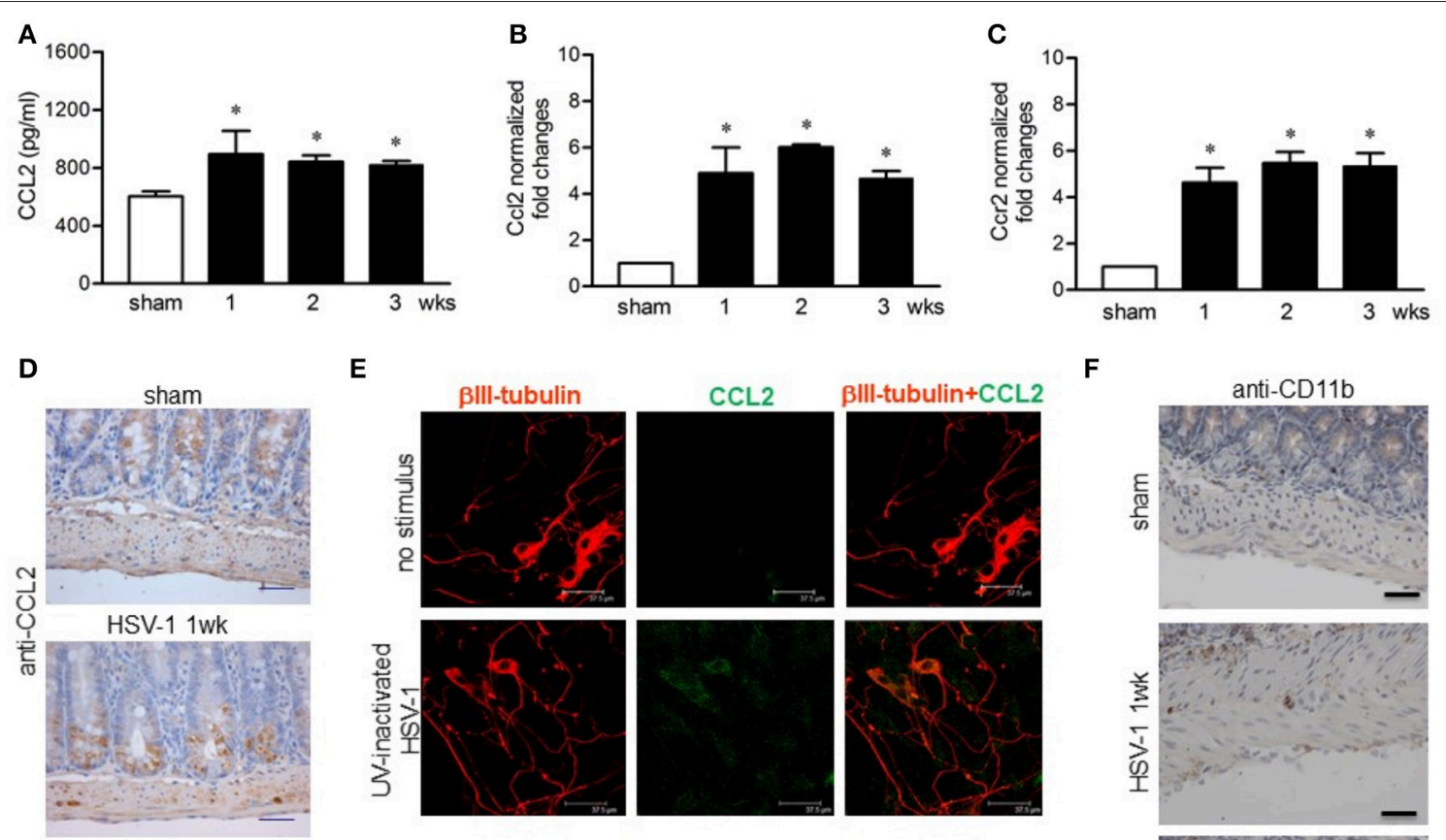

E

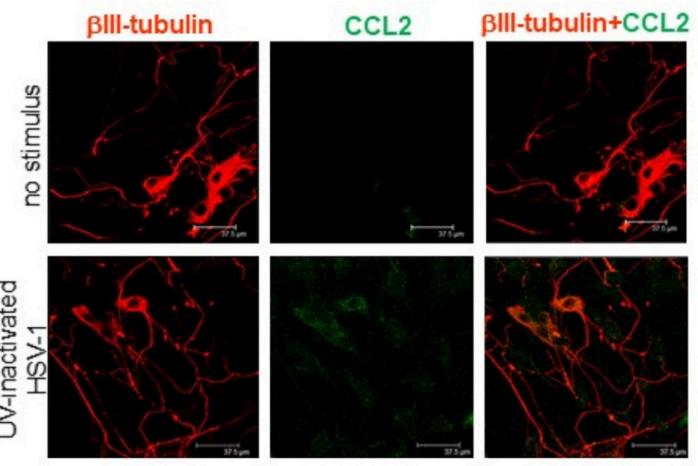

F

G
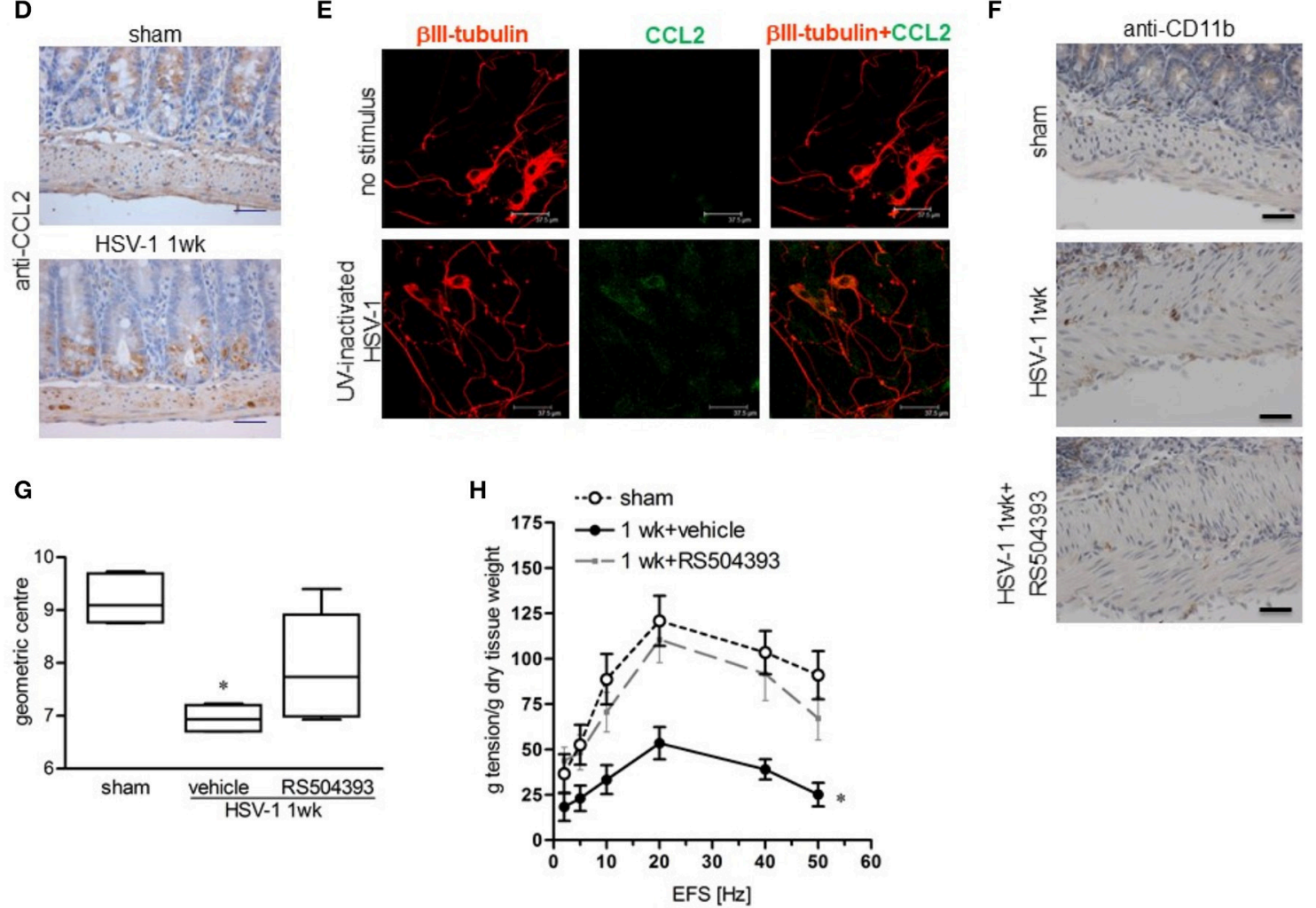

FIGURE 8 | CCL2 is required for macrophage recruitment and intestinal dysmotility during HSV-1 infection (A) CCL2 levels were quantified by ELISA in LMMP extracts obtained from sham and HSV-1 strain 16 infected mice. (B) Quantitative RT-PCR analysis of Ccl2 mRNA and (C) Ccr2 mRNA in LMMP from sham and HSV-1 strain 16 infected mice. Data were normalized to ribosomal 18S RNA (Rn18S) and reported as fold change. (D) Immunohistochemistry for CCL2 on sections of ileum collected from sham and HSV-1 strain 16 infected mice. Scale bars: $40 \mu \mathrm{m}$. (E) Enteric neurons cultured from LMMP of non-infected mice were exposed for $16 \mathrm{~h}$ to UV-inactivated HSV-1. Cells were then fixed and probed with anti- $\beta$ III tubulin and anti-CCL2 antibodies. Cells were visualized under a confocal microscope. Scale bar $=37.5 \mu \mathrm{m}$. (F) At 1-week post-infection, mice were treated with RS504393, a highly selective CCR2 chemokine receptor antagonist. Immunohistochemistry on sections of ileum revealed decreased infiltration of CD11 b ${ }^{+}$cells. Scale bars: $40 \mu \mathrm{m}$. Images are representative of three separate experiments. (G) At 1-week post-IG HSV-1 inoculum, RS504393 or vehicle treated mice were administered with non-absorbable FITC-labeled dextran and sacrificed 60 min later. Intestinal transit was reported as the geometric center of distribution of the fluorescent probe throughout the ileum. (H) EFS-elicited contractions in segments of ileum of sham and HSV-1 infected mice treated with RS504393 or vehicle. Data are represented as mean \pm SEM. $n=6-8$ mice per group. *Denotes $P<0.01$ compared to sham infected mice.

with HSV-1 produce a specific panel of cytokines to ensure viral defense and regulate immune response (Hill et al., 2009; Gianni et al., 2013). In the present study, we show that enteric neurons exposed to $\mathrm{HSV}-1$ secrete the chemokine CCL-2 to recruit and activate macrophages in the myenteric ganglia (Figures 7, 8) thus orchestrating the inflammatory response toward the pathogen. By promoting macrophage recruitment from the bloodstream to tissues, CCL2 plays a pivotal role in the pathogenesis of diseases characterized by mononuclear cells infiltration. For instance, Chen et al. reported a greater recruitment of inflammatory cells with significant larger areas of brain stroke during ischemic brain injury in mice over-expressing CCL2 as compared with wild-type controls (Chen et al., 2003). Accordingly, CCL2 deficiency reduces infiltration of macrophages into blood vessels, lung (Gosling et al., 1999; Dessing et al., 2007) and central nervous system in experimental animal models of inflammatory and neurodegenerative diseases (Huang et al., 2001; Muessel et al., 2002), including HSV-1 encephalitis (Kurt-Jones et al., 2004). In the gut, the activation of CCL2/CCR2 pathway has been 
described in several experimental colitis models (Yang et al., 2011) whereas CCL2 levels are increased in the colon of patients suffering from microscopic colitis and inflammatory bowel diseases (Arijs et al., 2011; Günaltay et al., 2015). Intriguingly, recent studies suggest that CCL2 contributes to the recruitment of specific macrophage subsets rather than in situ cell polarization thus shaping the extent of the inflammatory process (Takada et al., 2010).

Overall, in the present study we demonstrated that following an orogastric administration $\mathrm{HSV}-1$ reaches and infects enteric neurons. HSV-1 infected neurons directly recruit inflammatory macrophages through the CCL2/CCR2 pathway that releasing ROS trigger changes in ENS neuroplasticity causing gastrointestinal dysmotility. Our data are in line with recent studies assigning to enteric neurons the modulation and timely adaptation of gut macrophages to environmental challenges (Muller et al., 2014; Gabanyi et al., 2016). Disruption in neuroimmune communication frequently results in gastrointestinal dysfunction as largely described in the intestinal mucosa of IBS patients where the count of infiltrating immune cells, including mast cells in close proximity to nerve fibers is coupled to the intensity of abdominal pain and gastrointestinal discomfort (Barbara et al., 2014). We can speculate that acute or chronic exposure of enteric neurons to neurotropic viruses, such as HSV-1, permanently disturbs the interplay between the ENS and the immune cells thus contributing, along with

\section{REFERENCES}

Arijs, I., De Hertogh, G., Machiels, K., van Steen, K., Lemaire, K., Schraenen, A., et al. (2011). Mucosal gene expression of cell adhesion molecules, chemokines, and chemokine receptors in patients with inflammatory bowel disease before and after infliximab treatment. Am. J. Gastroenterol. 106, 748-761. doi: 10.1038/ajg.2011.27

Barbara, G., Cremon, C., and Stanghellini, V. (2014). Inflammatory bowel disease and irritable bowel syndrome: similarities and differences. Curr. Opin. Gastroenterol. 30, 352-358. doi: 10.1097/MOG.0000000000000070

Brun, P., Giron, M. C., Qesari, M., Porzionato, A., Caputi, V., Zoppellaro, C., et al. (2013). Toll-like receptor 2 regulates intestinal inflammation by controlling integrity of the enteric nervous system. Gastroenterology 145, 1323-1333. doi: 10.1053/j.gastro.2013.08.047

Brun, P., Giron, M. C., Zoppellaro, C., Bin, A., Porzionato, A., De Caro, R., et al. (2010). Herpes simplex virus type 1 infection of the rat enteric nervous system evokes small bowel neuromuscular abnormalities. Gastroenterology 138, 1790-1801. doi: 10.1053/j.gastro.2010.01.036

Brun, P., Gobbo, S., Caputi, V., Spagnol, L., Schirato, G., Pasqualin, M., et al. (2015). Toll like receptor-2 regulates production of glial-derived neurotrophic factors in murine intestinal smooth muscle cells. Mol. Cell. Neurosci. 68, 24-35. doi: 10.1016/j.mcn.2015.03.018

Buddingh, G. J., Schrum, D. R., Lancier, J. C., and Guildry, D. J. (1953). Studies of the natural history of herpes simplex infection. Pediatrics 11, 595-610.

Burgueño, J. F., Barba, A., Eyre, E., Romero, C., Neunlist, M., and Fernández, E. J. (2016). TLR2 and TLR9 modulate enteric nervous system inflammatory responses to lipopolysaccharide. J. Neuroinflammation 13:187. doi: 10.1186/s12974-016-0653-0

Chai, Q., She, R., Huang, Y., and Fu, Z. F. (2015). Expression of neuronal CXCL10 induced by rabies virus infection initiates infiltration of inflammatory cells, production of chemokines and cytokines, and enhancement of blood-brain barrier permeability. J. Virol. 89, 870-876. doi: 10.1128/JVI.02154-14

Chen, Y., Hallenbeck, J. M., Ruetzler, C., Bol, D., Thomas, K., Berman, N. E., et al. (2003). Overexpression of monocyte chemoattractant protein 1 in the brain exacerbates ischemic brain injury and is associated with neuronal damage itself, to the pathogenesis of gastrointestinal diseases.

\section{AUTHOR CONTRIBUTIONS}

All authors listed approved the manuscript for publication. $\mathrm{PB}$ and IC: designed research, performed research, analyzed data, and wrote the manuscript; $\mathrm{MQ}$ and $\mathrm{AK}$ : performed research; MG: analyzed data; PM, AP, VM, MS, GP, and AC critically read the manuscript; RS: provided Clodrolip and empty liposomes.

\section{FUNDING}

Italian Ministry of Education, Universities and Research (2007EN8F7T_002 to MG); Italian Ministry of Education, Universities and Research (2009HLNNRL_002 to IC); European Society of Clinical Microbiology and Infectious Diseases (ESCMID-Research Grant 2011 to PB). The funding agencies had no role in study design, data collection and interpretation, or the decision to submit the work for publication.

\section{ACKNOWLEDGMENTS}

We thank Gloria Sarasin and Anna Rambaldo for technical support with histological analysis.

recruitment of inflammatory cells. J. Cereb. Blood Flow Metab. 23, 748-755. doi: 10.1097/01.WCB.0000071885.63724.20

Cipriani, G., Gibbons, S. J., Kashyap, P. C., and Farrugia, G. (2016). Intrinsic gastrointestinal macrophages: their phenotype and role in gastrointestinal motility. Cell Mol. Gastroenterol. Hepatol. 2, 120-130. doi: 10.1016/j.jcmgh.2016.01.003

Coquenlorge, S., Duchalais, E., Chevalier, J., Cossais, F., Rolli-Derkinderen, M., and Neunlist, M. (2014). Modulation of lipopolysaccharide-induced neuronal response by activation of the enteric nervous system. J. Neuroinflammation 11:202. doi: 10.1186/s12974-014-0202-7

Dessing, M. C., van der Sluijs, K. F., Florquin, S., and van der Poll, T. (2007). Monocyte chemoattractant protein 1 contributes to an adequate immune response in influenza pneumonia. Clin. Immunol. 125, 328-336. doi: 10.1016/j.clim.2007.08.001

De Visser, Y. P., Walther, F. J., Laghmani, E. H., van der Laarse, A., and Wagenaar, G. T. M. (2010). Apelin attenuates hyperoxic lung and heart injury in neonatal rats. Am. J. Respir. Crit. Care Med. 182, 1239-1250. doi: 10.1164/rccm.200909-13610C

Dosa, S., Castellanos, K., Bacsa, S., Gagyi, E., Kovacs, S. K., Valyi-Nagy, K., et al. (2011). Chronic progressive deficits in neuron size, density and number in the trigeminal ganglia of mice latently infected with herpes simplex virus. Brain Pathol. 21, 583-593. doi: 10.1111/j.1750-3639.2011.00485.x

Du, Y., Deng, W., Wang, Z., Ning, M., Zhang, W., Zhou, Y., et al. (2017). Differential subnetwork of chemokines/cytokines in human, mouse, and rat brain cells after oxygen-glucose deprivation. J. Cereb. Blood Flow Metab. 37, 1425-1434. doi: 10.1177/0271678X16656199

Ellermann-Eriksen, S. (2005). Macrophages and cytokines in the early defence against herpes simplex virus. Virol. J. 2:59. doi: 10.1186/1743-422X-2-59

Gabanyi, I., Muller, P. A., Feighery, L., Oliveira, T. Y., Costa-Pinto, F. A., and Mucida, D. (2016). Neuro-immune interactions drive tissue programming in intestinal macrophages. Cell 164, 378-391. doi: 10.1016/j.cell.2015. 12.023

Galeazzi, F., Lovato, P., Blennerhassett, P. A., Haapala, E. M., Vallance, B. A., and Collins, S. M. (2001). Neural change in Trichinellainfected mice is MHC II independent and involves M-CSF-derived 
macrophages. Am. J. Physiol. Gastrointest. Liver Physiol. 281, G151-G158. doi: 10.1152/ajpgi.2001.281.1.G151

Garcia, J. H., Wagner, S., Liu, K. F., and Hu, X. J. (1995). Neurological deficit and extent of neuronal necrosis attributable to middle cerebral artery occlusion in rats. Stat. Valid. Stroke 26, 627-634. doi: 10.1161/01.STR.26.4.627

Gesser, R. M., and Koo, S. C. (1997). Latent herpes simplex virus type 1 gene expression in ganglia innervating the human gastrointestinal tract. J. Virol. 71, 4103-4106.

Gianni, T., Leoni, V., and Campadelli-Fiume, G. (2013). Type I interferon and NF- $\mathrm{B}$ activation elicited by herpes simplex virus $\mathrm{gH} / \mathrm{gL}$ via $\alpha \mathrm{v} \beta 3$ integrin in epithelial and neuronal cell lines. J. Virol. 87, 13911-13916. doi: 10.1128/JVI.01894-13

Ginhoux, F., Greter, M., Leboeuf, M., Nandi, S., See, P., Gokhan, S., et al. (2010). Fate mapping analysis reveals that adult microglia derive from primitive macrophages. Science 330, 841-845. doi: 10.1126/science.1194637

Gosling, J., Slaymaker, S., Gu, L., Tseng, S., Zlot, C. H., Young, S. G., et al. (1999). MCP-1 deficiency reduces susceptibility to atherosclerosis in mice that overexpress human apolipoprotein B. J. Clin. Invest. 103, 773-778. doi: $10.1172 /$ JCI5624

Günaltay, S., Kumawat, A. K., Nyhlin, N., Bohr, J., Tysk, C., Hultgren, O., et al. (2015). Enhanced levels of chemokines and their receptors in the colon of microscopic colitis patients indicate mixed immune cell recruitment. Mediators Inflamm. 2015:132458. doi: 10.1155/2015/132458

Hill, J. M., Zhao, Y., Clement, C., Neumann, D. M., and Lukiw, W. J. (2009). HSV-1 infection of human brain cells induces miRNA-146a and Alzheimer-type inflammatory signaling. Neuroreport 20, 1500-1505. doi: 10.1097/WNR.0b013e3283329c05

Huang, D. R., Wang, J., Kivisakk, P., Rollins, B. J., and Ransohoff, R. M. (2001). Absence of monocyte chemoattractant protein 1 in mice leads to decreased local macrophage recruitment and antigen-specific T helper cell type 1 immune response in experimental autoimmune encephalomyelitis. J. Exp. Med. 193, 713-726. doi: 10.1084/jem.193.6.713

Hurst, S. M., and Collins, S. M. (1994). Mechanism underlying tumor necrosis factor-alpha suppression of norepinephrine release from rat myenteric plexus. Am. J. Physiol. 266, G1123-G1129. doi: 10.1152/ajpgi.1994.266.6.G1123

Kaufman, H. E., Azcuy, A. M., Varnell, E. D., Sloop, G. D., Thompson, H. W., and Hill, J. M. (2005). HSV-1 DNA in tears and saliva of normal adults. Invest. Ophthalmol. Vis. Sci. 46, 241-247. doi: 10.1167/iovs.04-0614

Khan, I., and Collins, S. M. (1994). Expression of cytokines in the longitudinal muscle myenteric plexus of the inflamed intestine of rat. Gastroenterology 107, 691-700. doi: 10.1016/0016-5085(94)90116-3

Khoury-Hanold, W., Yordy, B., Kong, P., Kong, Y., Ge, W., Szigeti-Buck, K., et al. (2016). Viral spread to enteric neurons links genital HSV-1 infection to toxic megacolon and lethality. Cell Host Microbe. 19, 788-799. doi: 10.1016/j.chom.2016.05.008

Kitagawa, K., Wada, T., Furuichi, K., Hashimoto, H., Ishiwata, Y., Asano, M., et al. (2004). Blockade of CCR2 ameliorates progressive fibrosis in kidney. Am. J. Pathol. 165, 237-246. doi: 10.1016/S0002-9440(10)63292-0

Kodukula, P., Liu, T., Rooijen, N. V., Jager, M. J., and Hendricks, R. L. (1999). Macrophage control of herpes simplex virus type 1 replication in the peripheral nervous system. J. Immunol. 162, 2895-2905.

Koyuncu, O., Hogue, I. B., and Enquist, L. W. (2013). Virus infections in the nervous system. Cell Host Microbe. 13, 379-393. doi: 10.1016/j.chom.2013.03.010

Kramer, M. F., Cook, W. J., Roth, F. P., Zhu, J., Holman, H., Knipe, D. M., et al. (2003). Latent herpes simplex virus infection of sensory neurons alters neuronal gene expression. J. Virol. 77, 9533-9541. doi: 10.1128/JVI.77.17.9533-954 1.2003

Krisky, D. M., Wolfe, D., Goins, W. F., Marconi, P. C., Ramakrishnan, R., Mata, M., et al. (1998). Deletion of multiple immediate-early genes from herpes simplex virus reduces cytotoxicity and permits long-term gene expression in neurons. Gene Ther. 5, 593-1603. doi: 10.1038/sj.gt.3300766

Kumar, M., Verma, S., and Nerurkar, V. R. (2010). Pro-inflammatory cytokines derived from West Nile virus (WNV)-infected SK-N-SH cells mediate neuroinflammatory markers and neuronal death. J. Neuroinflammation 7:73. doi: 10.1186/1742-2094-7-73

Kurt-Jones, E. A., Chan, M., Zhou, S., Wang, J., Reed, G., Bronson, R., et al. (2004). Herpes simplex virus 1 interaction with Toll-like receptor 2 contributes to lethal encephalitis. Proc. Natl. Acad. Sci. U.S.A. 101, 1315-1320. doi: 10.1073/pnas.0308057100

LaBuda, C. J., Koblish, M., Tuthill, P., Dolle, R. E., and Little, P. J. (2006). Antinociceptive activity of the selective iNOS inhibitor AR-C102222 in rodent models of inflammatory, neuropathic and post-operative pain. Eur. J. Pain 10, 505-512. doi: 10.1016/j.ejpain.2005.07.004

Liem, R. K., and Messing, A. (2009). Dysfunctions of neuronal and glial intermediate filaments in disease. J. Clin. Invest. 119, 1814-1824. doi: $10.1172 / \mathrm{JCI} 38003$

Lindberg, G., Törnblom, H., Iwarzon, M., Nyberg, B., Martin, J. E., and Veress, B. (2009). Full-thickness biopsy findings in chronic intestinal pseudo-obstruction and enteric dysmotility. Gut 58, 1084-1090. doi: 10.1136/gut.2008.148296

Marconi, P., Fraefel, C., and Epstein, A. L. (2015). Herpes simplex virus type 1 (HSV-1)-derived recombinant vectors for gene transfer and gene therapy. Methods Mol. Biol. 1254, 269-293. doi: 10.1007/978-1-4939-2152-2_20

Marconi, P., Manservigi, R., and Epstein, A. L. (2010). HSV-1-derived helperindependent defective vectors, replicating vectors and amplicon vectors, for the treatment of brain diseases. Curr. Opin. Drug Discov. Devel. 13, 169-183.

Martínez, V., Wang, L., Rivier, J. E., Vale, W., and Taché, Y. (2002). Differential actions of peripheral corticotropin-releasing factor (CRF), Urocortin II, and Urocortin III on gastric emptying and colonic transit in mice: role of CRF receptor subtypes 1 and 2. J. Pharmacol. Exp. Ther. 301, 611-617. doi: 10.1124/jpet.301.2.611

Melchjorsen, J. (2012). Sensing herpes: more than toll. Rev. Med. Virol. 22, 106-121. doi: 10.1002/rmv.716

Menendez, C. M., Jinkins, J. K., and Carr, D. J. (2016). Resident T cells are unable to control herpes simplex virus-1 activity in the brain ependymal region during latency. J. Immunol. 197, 1262-1275. doi: 10.4049/jimmunol.1600207

Miller, C. S., and Danaher, R. J. (2008). Asymptomatic shedding of herpes simplex virus (HSV) in the oral cavity. Oral Surg. Oral Med. Oral Pathol. Oral Radiol. Endod. 105, 43-50. doi: 10.1016/j.tripleo.2007.06.011

Muessel, M. J., Klein, R. M., Wilson, A. M., and Berman, N. E. (2002) Ablation of the chemokine monocyte chemoattractant protein-1 delays retrograde neuronal degeneration, attenuates microglial activation, and alters expression of cell death molecules. Brain Res. Mol. Brain Res. 103, 12-27. doi: 10.1016/S0169-328X(02)00158-4

Muller, P. A., Koscsó, B., Rajani, G. M., Stevanovic, K., Berres, M. L., Hashimoto, D., et al. (2014). Crosstalk between muscularis macrophages and enteric neurons regulates gastrointestinal motility. Cell 158, 300-313. doi: 10.1016/j.cell.2014.04.050

Nakamura, T., Prikhodko, O. A., Pirie, E., Nagar, S., Akhtar, M. W., Oh, C. K., et al. (2015). Aberrant protein S-nitrosylation contributes to the pathophysiology of neurodegenerative diseases. Neurobiol. Dis. 84, 99-108. doi: 10.1016/j.nbd.2015.03.017

Phillips, R. J., and Powley, T. L. (2012). Macrophages associated with the intrinsic and extrinsic autonomic innervation of the rat gastrointestinal tract. Auton. Neurosci. 169, 12-27. doi: 10.1016/j.autneu.2012.02.004

Rand, K. H., Berns, K. I., and Rayfield, M. A. (1984). Recovery of herpes simplex type 1 from the celiac ganglion after renal transplantation. South. Med. J. 77, 403-404. doi: 10.1097/00007611-198403000-00039

Serio, R., Zizzo, M. G., and Mulè, F. (2003). Nitric oxide induces muscular relaxation via cyclic GMP-dependent and -independent mechanisms in the longitudinal muscle of the mouse duodenum. Nitric Oxide 8, 48-52. doi: 10.1016/S1089-8603(02)00144-1

Straus, S. E. (2000). "Introduction to herpesviridae," in Principles and Practice of Infectious Diseases, eds G. Mandel, J. E. Bennett, and R. Dolin (London: Churchill Livingstone), 1557-1564.

Swanson, P. A., and McGavern, D. B. (2015). Viral diseases of the central nervous system. Curr. Opin. Virol. 11, 44-54. doi: 10.1016/j.coviro.2014.12.009

Takada, Y., Hisamatsu, T., Kamada, N., Kitazume, M. T., Honda, H., Oshima, Y., et al. (2010). Monocyte chemoattractant protein-1 contributes to gut homeostasis and intestinal inflammation by composition of IL10-producing regulatory macrophage subset. J. Immunol. 184, 2671-2676. doi: 10.4049/jimmunol.0804012

Tischfield, M. A., and Engle, E. C. (2010). Distinct alpha- and beta-tubulin isotypes are required for the positioning, differentiation and survival of neurons: new support for the "multi-tubulin" hypothesis. Biosci. Rep. 30, 319-330. doi: 10.1042/BSR20100025 
Törnblom, H., Lindberg, G., Nyberg, B., and Veress, B. (2002). Fullthickness biopsy of the jejunum reveals inflammation and enteric neuropathy in irritable bowel syndrome. Gastroenterology 123, 1972-1979. doi: 10.1053/gast.2002.37059

van Velzen, M., Jing, L., Osterhaus, D., Sette, A., Koelle, D. M., and Verjans, G. M. (2013). Local CD4 and CD8 T-cell reactivity to HSV-1 antigens documents broad viral protein expression and immune competence in latently infected human trigeminal ganglia. PLoS Pathog. 9:e1003547. doi: 10.1371/journal.ppat.1003547

Virgin, H. W., Wherry, E. J., and Ahmed, R. (2009). Redefining chronic viral infection. Cell 138, 30-50. doi: 10.1016/j.cell.2009.06.036

Wehner, S., Behrendt, F. F., Lyutenski, B. N., Lysson, M., Bauer, A. J., Hirner, A., et al. (2007). Inhibition of macrophage function prevents intestinal inflammation and postoperative ileus in rodents. Gut 56, 176-185. doi: 10.1136/gut.2005.089615

White, K. A., Hutton, S. R., Weimer, J. M., and Sheridan, P. A. (2016). Diet-induced obesity prolongs neuroinflammation and recruits CCR2+ monocytes to the brain following herpes simplex virus (HSV)-1 latency in mice. Brain Behav. Immun. 57, 68-78. doi: 10.1016/j.bbi.2016.06.007

Wilson, A. C., and Mohr, I. (2012). A cultured affair: HSV latency and reactivation in neurons. Trends Microbiol. 20, 604-611. doi: 10.1016/j.tim.2012. 08.005
Yang, Y., Wang, H., Dou, Y., Wang, Y., Han, G., Wang, R., et al. (2011). Colitogenic role of tumour necrosis factor (TNF) receptors in trinitrobenzene sulphonic acid colitis: TNF-R1 ablation does not affect systemic inflammatory response. Clin. Exp. Immunol. 165, 372-382. doi: 10.1111/j.1365-2249.2011.04413.x

Zeisberger, S. M., Odermatt, B., Marty, C., Zehnder-Fjällman, A. H., Ballmer-Hofer, K., and Schwendener, R. A. (2006). Clodronate-liposomemediated depletion of tumour-associated macrophages: a new and highly effective antiangiogenic therapy approach. Br. J. Cancer 95, 272-281. doi: $10.1038 /$ sj.bjc. 6603240

Conflict of Interest Statement: The authors declare that the research was conducted in the absence of any commercial or financial relationships that could be construed as a potential conflict of interest.

Copyright (C) 2018 Brun, Qesari, Marconi, Kotsafti, Porzionato, Macchi, Schwendener, Scarpa, Giron, Palù, Calistri and Castagliuolo. This is an openaccess article distributed under the terms of the Creative Commons Attribution License (CC BY). The use, distribution or reproduction in other forums is permitted, provided the original author(s) and the copyright owner are credited and that the original publication in this journal is cited, in accordance with accepted academic practice. No use, distribution or reproduction is permitted which does not comply with these terms. 